\title{
MICROFIBRES OF CONDUCTING POLYTHIOPHENE AND \\ BIODEGRADABLE POLY(ESTER UREA) FOR SCAFFOLDS
}

Marc Planellas, ${ }^{1, \star}$ Maria M. Pérez-Madrigal, ${ }^{1,2,}$ Luís J. del Valle, ${ }^{1}$ Sophio Kobauri, ${ }^{3}$ Ramaz Katsarava, ${ }^{3}$ Carlos Alemán,,${ }^{1,2}$ and Jordi Puiggalí ${ }^{1,2, *}$

${ }^{1}$ Departament d'Enginyeria Química, Universitat Politècnica de Catalunya, Av. Diagonal 647, Barcelona E-08028, SPAIN

${ }^{2}$ Center for Research in Nano-Engineering, Universitat Politècnica de Catalunya, Campus Sud, Edifici C', C/Pasqual i Vila s/n, Barcelona E-08028, Spain

${ }^{3}$ Institute of Chemistry and Molecular Engineering, Agricultural University of Georgia, 13 km. David Aghmashenebeli Alley, Tblisi 0159, GEORGIA

- These authors contributed equally to this work and both occupy the first author position.

*Correspondence to: J. Puiggalí (jordi.puiggali@upc.es) and C. Alemán (carlos.aleman@upc.edu) 


\begin{abstract}
Hybrid scaffolds constituted by a mixture of conducting and biodegradable polymers have been obtained by the electrospinning technique. Specifically, poly(3-thiophene metyl acetate) (P3TMA) and a copolymer derived from L-leucine which bears ester, urea and amide groups (PEU-co-PEA) have been employed. Both polymers have been selected because of their intrinsic properties and their high solubility in organic solvents. The biodegradable polymer renders continuous and homogeneous microfibers in most of the electrospinning conditions tested, appearing as an ideal carrier for the polythiophene derivative.

A spontaneous phase separation has been observed for concentrated solutions of PEU-coPEA and P3TMA in chloroform:methanol mixtures. The dense phase results enriched on the conducting polymer and can be successfully electrospun giving rise to scaffolds with up to 90 wt-\% of P3TMA. Morphologic observations have indicated that continuous and regular microfibers are attained despite the high conducting polymer content. P3TMA presents a high doping level and leads to stable electrospun scaffolds by the simple addition of a low percentage of a high molecular weight carrier. The resulting scaffolds are practically amorphous and thermally stable, presenting also a pronounced electrochemical response and being electrochemically active. Thus, the formation of polarons and bipolarons at specific positions, the ability to exchange charge reversibly and the electrical stability of hybrid PEUco-PEA/P3TMA electrospun scaffolds and P3TMA alone are practically the same.
\end{abstract}

Keywords: Biodegradable polymer; Conducting polymer; Electrospinning; Hybrid scaffold; Poly(ester urea); Polythiophene derivative 


\section{INTRODUCTION}

Materials able to combine biodegradable and conducting properties have highly promising applications in biomedicine. Stimulation of either the proliferation or differentiation of various cell types and the development of time controlled drug release systems are clear examples of their potential uses. Among conducting materials, conducting polymers (CPs) are potential candidates for the preparation of scaffolds. ${ }^{1-3}$ This is because the intrinsic electrical and electrochemical (i.e. eletroactivity) properties of these organic materials enhance cell proliferation at polymer-tissue interface through electrochemical stimulation and an ionexchange mechanism, respectively. ${ }^{1-3}$ However, CPs are non-degrabable materials and, therefore, a challenging task is to introduce biodegradability for their use as scaffolds. Different strategies have been explored to ensure the biodegradability of CP-containing scaffolds. ${ }^{1-3}$ For example, some efforts have been focused on the synthesis of hybrid polymers that combine conducting and degradable units. ${ }^{4,5}$ Other alternatives correspond to the use of degradable polymers as templates for a subsequent deposition of $\mathrm{CPs}^{6-8}$ and also the development of nanostructured blends of conducting and biodegradable polymers. ${ }^{9,10}$

Electrospinning is a versatile technique that offers great potential for the fabrication of hybrid scaffolds with the porosity required for effective tissue regeneration applications. ${ }^{11}$ Unfortunately, the preparation of conductive micro/nanofibers by direct electrospinning is not a trivial task due to the low solubility, fast crystallization and low molecular weight of CPs. Therefore, fiber morphology usually becomes discontinuous and shows lots of beads ${ }^{12}$ that, in some cases, can be minimized using a coaxial setup to prevent crystallization at the nozzle tip. $^{13}$

These morphologic problems can be overcome by blending the $\mathrm{CP}$ with another electrospinnable polymer (used as a carrier). The detriment of the electronic properties is the major inconvenience of this strategy while the specific properties contributed by the carrier 
(e.g. biodegradability and biocompatibility) represent new advantages for the development of biomedical materials.

Poly(3-thiophene methyl acetate) (P3TMA) is an electroactive polythiophene derivative bearing a carboxylate substituent in the 3-position of the heterocyclic ring (Figure 1) that provides good solubility in some organic solvents such as $\mathrm{CHCl}_{3}$, THF or DMSO. This characteristic has been exploited to prepare a common solution with high molecular weight biodegradable polymers, as for example poly(tetramethylene succinate) and polylactide, and fabricated stable free-standing nanomembranes and nanofiber scaffolds that combine properties of each component. ${ }^{14-17}$ The bioactivity of such P3TMA-containing scaffolds as well as of individual P3TMA was repeatedly proved through cellular adhesion and proliferation assays.

$\alpha$-Amino acid-based polymers (AABPs) are receiving great attention as new biodegradable materials for biomedical applications due to their favorable combination of properties. Among AABPs poly(ester amide)s ${ }^{18-23}$ (PEAs) are the most studied ones. Relatively new and less investigated class of AABPs are poly(ester urea)s (PEUs) obtained for the first time by Katsarava and co-workers via solution active polycondensation. ${ }^{24}$ Later on this team showed that high-molecular-weight PEUs with desirable material properties could be synthesized via interfacial polycondensation using phosgene or triphosgen as starting monomers. ${ }^{25}$ In this way, a L-leucine based PEU was successfully used for preparing nanofibers loaded with antibacterials, ${ }^{26}$ while L-phenylalanine based PEUs were employed to develop high-strength materials as promising bone substitutes. ${ }^{27,28}$ In general PEAs and PEUs are promising materials since, strong intermolecular hydrogen bond interactions can be established between amide or urea groups, giving rise to good thermal and mechanical properties. Furthermore, degradability of these materials can also be guaranteed by the presence of hydrolysable ester groups, while the selection of adequate constitutive units may provide biocompatibility and 
nontoxic hydrolysis by-products. The high versatility of natural $\alpha$-amino acids with different pendent groups and the possibility of employing diols along with dicarboxylic acid units with aliphatic segments of different lengths lead to a tremendous variety of materials with easily customized properties.

The PEU derived from carbonic acid, L-leucine, and 1,6-hexanediol (named 1L6 in Figure 1a) showed interesting properties and appeared suitable as implantable surgical devices (e.g. vascular stents and hard tissue replacement implants). Specifically, a tensile strength at yield, elongation at break and Young's modulus of $21 \mathrm{MPa}, 114 \%$ and $622 \mathrm{MPa}$, respectively were reported together with melting temperature of $114{ }^{\circ} \mathrm{C}$ and glass transition temperature of 47 ${ }^{\circ} \mathrm{C} .{ }^{25}$ Solubility in organic solvents and properties like molecular flexibility can be easily improved by incorporating a small ratio of dicarboxylic acid units with high methylene content (e.g. sebacic acid). In this case, copolymers contain both urea and amide groups (PEU-co-PEA copolymers) in a proportion that can be easily tuned following a simple two step procedure (Figure 1a) based on the interfacial polycondensation method previously reported for PEUs. ${ }^{25}$

The goal of the present work is to develop hybrid scaffolds with the maximum load of P3TMA using a new biodegradable PEU-co-PEA as electrospinable carrier. Intermolecular interactions between the polar moieties of the two polymers are expected to play a crucial role and might achieve a high concentration of the $\mathrm{CP}$ in the electrospinable solution might be achieved. Results discussed below evidence that the poly(ester urea) carrier has allowed us to obtain stable microfibers containing $90 \mathrm{wt}-\%$ of the biocompatible polythiophene used in this work. Accordingly, the prepared electrospun 3D scaffolds exhibit an electrochemical activity similar to that of pure P3TMA. It should be remarked that, in absence of a carrier, the latter polythiophene derivative cannot be used for the preparation of 3D scaffolds since its mechanical integrity and intrinsic biodegradability is practically null. Recent studies have 
evidenced that P3TMA can be easily detached from scaffolds when it is combined with biodegradable polymers, ${ }^{15,29}$ which is a very interesting property for the fabrication of useful CP-enriched electroactive scaffolds. In addition, P3TMA has been selected not only because of its high biocompatibility but also because of its electrochemical activity, the latter being responsible of its excellent behaviour as bioactive matrix (i.e. cellular adhesion and proliferation are significantly enhanced by the ion-exchange ability of this $\mathrm{CP}$ at the cellpolymer interface). ${ }^{14-16,29}$

\section{EXPERIMENTAL SECTION}

\section{Materials}

All chemicals were ACS grade and used without further purification. The di- $p$-toluenesulfonic acid salt of bis-L-leucine-hexane-1,6-diester (L6) was prepared, as reported previousely, ${ }^{30}$ by direct condensation of $26.24 \mathrm{~g}(0.2 \mathrm{~mol})$ of L-leucine with $11.8 \mathrm{~g}(0.1 \mathrm{~mol})$ of 1,6-hexanediol in refluxing benzene $(500 \mathrm{~mL})$ and in the presence of a slight excess $39.95 \mathrm{~g}(0.21 \mathrm{~mol}))$ of $p$ toluenesulfonic acid monohydrate. Reaction was prolonged for $16 \mathrm{~h}$ until $7.4 \mathrm{~mL}(0.41 \mathrm{~mol})$ of water was collected in Dean-Stark trap. The reaction mixture was then cooled to room temperature and filtered off. The obtained white solid was dried from benzene, washed with water to remove excess $p$-toluenesulfonic acid, recrystallized from water and dried at $100^{\circ} \mathrm{C}$ in an oven equipped with a fan. Yield 59.25 g (86\%), m.p. $189-191{ }^{0}$ C, reported m.p. 190$192 .^{30}$

\section{Polymer synthesis}

\section{PEU-co-PEA copolymer}

To a suspension of $13.78 \mathrm{~g}(0.02 \mathrm{~mol})$ of $\mathrm{L} 6$ in $150 \mathrm{~mL}$ of water, $6.36 \mathrm{~g}$ of anhydrous sodium carbonate ( 0.06 mol, 3.0 equiv.) was added and stirred at room temperature for about 
30-40 $\mathrm{min}\left(\right.$ The $1^{\text {st }}$ solution). In parallel, $5.52 \mathrm{~g}(0.0186 / 3 \mathrm{~mol}, 93.0 \mathrm{~mol} . \%)$ of triphosgene (purity $98.5 \%)$ and $0.335 \mathrm{~g}(0.0014 \mathrm{~mol}, 7.0 \mathrm{~mol} . \%)$ of sebacoyl chloride (purity $98.5 \%$ ) was dissolved in $65.0 \mathrm{~mL}$ of chloroform stabilized by amylene (The $2^{\text {nd }}$ solution). The $1^{\text {st }}$ solution was placed into a reactor for interfacial polycondensation and the $2^{\text {nd }}$ solution at room temperature $\left(20^{\circ} \mathrm{C}\right)$ was quickly added at one go and the water/organic mixture was stirred vigorously for about 15-20 min. The stirring was stopped and then the mixture was transferred to a separatory funnel and allowed to form two layer system. The lower layer, that represents the polymers solution in chloroform, was collected, washed 3-times $(3 \times 0.6 \mathrm{~L}-$ the chloroform layer was separated after each portion of washing water was added) with distilled water to remove the salts - sodium chloride, sodium carbonate/bicarbonate, and sodium $p$ toluenesulfonate. After washing chloroform layer was separated again, dried over anhydrous $\mathrm{Na}_{2} \mathrm{SO}_{4}(100.0 \mathrm{~g})$ and filtered off. The obtained chloroform solution was placed in glass vessel and chloroform ( $c$ a. 55-60 mL) was removed by distillation under atmospheric pressure. Afterwards, $600 \mathrm{~mL}$ of hot water $\left(\mathrm{ca} .70^{\circ} \mathrm{C}\right)$ was added to the viscous polymer solution and the rubbery mass formed was removed from the glass vessel and placed onto the Teflon ${ }^{\circledR}$ plate, squeezed to remove and pour out the residual water, the plate is placed in an oven equipped with a fan and dried at $100^{\circ} \mathrm{C}$. Finally, the polymer was vacuum-dried at $100^{\circ} \mathrm{C}$ up to constant weight, a yield of $95 \%$ being obtained with this procedure.

The copolymer PEU-co-PEA composed of 93 mol.\% of poly(ester urea) 1L6 and 7 mol.\% of poly(ester amide) 8L6 is labelled as $\mathbf{1} \mathbf{L 6}_{\mathbf{9 3}} \mathbf{- 8 \mathbf { L 6 } _ { 7 }}$ (1 for carbonyl, 8 for sebacoyl, L for Lleucine, and 6 for 1,6-hexanediol units).

\section{P3TMA conducting polymer}

The 3-thiophene methyl acetate (3TMA) monomer was obtained with a 74\% yield by refluxing 3TAA in dry methanol for 24 hours at a temperature of $90{ }^{\circ} \mathrm{C} .{ }^{14}$ The polythiophene derivative, P3TMA (Figure 1b), was subsequently prepared by a chemical oxidative coupling 
polymerization in dry chloroform following the procedure described by Kim et al. ${ }^{31}$ Anhydrous ferric chloride $\left(\mathrm{FeCl}_{3}\right)$ was used as oxidant and dopant. The polymerization yield was ca. $61 \%$ after removing the residual oxidant and oligomers.

\section{Measurements}

Molecular weight was estimated by gel permeation chromatography (GPC) using a liquid chromatograph (Shimadzu, model LC-20AD) equipped with a LC solution GPC software (Shimadzu). A PL HFIP gel $9 \mu \mathrm{m}$ column (Polymer Lab 300x7.5mm) at $40{ }^{\circ} \mathrm{C}$ and a refractive index detector (Shimadzu RID-10A) were employed. The polymer was dissolved and eluted in 1,1,1,3,3,3-hexafluoroisopropanol (HFIP) containing CF3COONa (0.05 M) at a flow rate of $1 \mathrm{~mL} / \mathrm{min}$ (injected volume $20 \mu \mathrm{L}$, sample concentration $2-6 \mathrm{mg} / \mathrm{mL}$ ). The number and weight average molecular weights and molar-mass dispersities were calculated using poly(methyl methacrylate) standards. Deconvolution of GPC curves was performed with the PeakFit v4 program by Jandel Scientific Software using an asymmetric function known as "asymmetric double sigmoidal".

Infrared absorption spectra were recorded with a FTIR 4100 Fourier Transform spectrometer from Jasco. A MKII Golden Gate attenuated total reflection (ATR) accessory from Specac was employed.

${ }^{1}$ H-NMR spectra were acquired with a Bruker AMX-300 spectrometer operating at 300.1 MHz. Chemical shifts were calibrated using tetramethylsilane as an internal standard. Deuterated chloroform $\left(\mathrm{CDCl}_{3}\right)$ was used as the solvent at room temperature.

X-Ray powder diffraction patterns were obtained with a PANalytical X'Pert PRO MPD $\theta / \theta$ powder diffractometer with $\mathrm{Cu} \mathrm{K}_{\alpha}$ radiation $(\lambda=1.5418 \AA)$ and a silicon monocrystal sample holder. Operating voltage and current were $40 \mathrm{kV}$ and $50 \mathrm{~mA}$, respectively. Thin samples sandwiched between low absorbing films were used. 
Calorimetric data were obtained by differential scanning calorimetry with a TA Instruments Q100 series. Experiments were conducted at a heating rate of $10{ }^{\circ} \mathrm{C} / \mathrm{min}$ under a flow of dry nitrogen with a sample weight of approximately $5 \mathrm{mg}$, while calibration was performed with indium.

Thermal degradation was studied at a heating rate of $10^{\circ} \mathrm{C} / \mathrm{min}$ with around $5 \mathrm{mg}$ samples in a Q50 thermogravimetric analyzer of TA Instruments and under a flow of dry nitrogen. Test temperatures ranged from 50 to $600{ }^{\circ} \mathrm{C}$.

\section{Electrospinning}

Electrospun fibers were collected on a target placed at different distances $(10-25 \mathrm{~cm})$ from the needle tip (inside diameter of $0.84 \mathrm{~mm}$ ). The voltage was varied between 10 and $30 \mathrm{kV}$ and applied to the target using a high-voltage supply (Gamma High Voltage Research, ES305W). Polymer solutions were delivered via a KDS100 infusion syringe pump (KD Scientific, USA) to control the mass-flow rate (from 0.5 to $4 \mathrm{~mL} / \mathrm{h}$ ). All electrospinning experiments were carried out at room temperature. Electrospun fiber scaffolds were prepared using optimized parameters (i.e. needle tip-collector distance, voltage and flow rate) and solvent conditions (i.e. solvent ratio, and polymer concentrations).

\section{Morphology of electrospun scaffolds}

Optical microscopy studies were performed with a Zeiss Axioskop 40 microscope. Micrographs were taken with a Zeiss AxiosCam MRC5 digital camera.

Detailed inspection of texture and morphology of electrospun samples was conducted by scanning electron microscopy using a Focus Ion Beam Zeiss Neon 40 instrument (Carl Zeiss, Germany). Carbon coating was accomplished using a Mitec K950 Sputter Coater fitted with a film thickness monitor $k 150 \mathrm{x}$. Samples were visualized at an accelerating voltage of $5 \mathrm{kV}$. 
Diameter of electrospun fibers was measured with the SmartTiff software from Carl Zeiss SMT Ltd.

\section{Determination of P3TMA doping level}

The doping level (DL) of chemically synthesized P3TMA was determined electrochemically by carrying out chronopotenciometry assays under a constant cathodic current intensity that varied from $-0.1 \mathrm{~mA}$ to $-2 \mathrm{~mA}$ (current density: -0.025 to $-0.5 \mathrm{~mA} / \mathrm{cm}^{2}$ ). This procedure aimed to reduce the P3TMA film completely. Electrochemical experiments were conducted on a PGSTAT302N AUTOLAB potentiostat using a three-electrode onecompartment cell under nitrogen atmosphere at room temperature. The cell was filled with 25 $\mathrm{mL}$ of acetonitrile with $0.1 \mathrm{M} \mathrm{LiClO}_{4}$.

Steel sheets, which were used as working electrodes, were cleaned with acetone and edges were carefully protected with an epoxy resin. Thus, only controlled areas $\left(2 \times 2 \mathrm{~cm}^{2}\right)$ were covered with P3TMA and exposed to the electrochemical medium. A P3TMA solution of 0.1 $\mathrm{g} / \mathrm{mL}$ was obtained by dissolving P3TMA powder in chloroform. As a pre-treatment, P3TMA underwent mild sonication for 10 minutes before (as a powder) and after its dissolution. Following the pre-treatment, the solution was filtered with cotton as a separation barrier. Then, the resulting solution was used for solvent-casting deposition. Specifically, $35 \mu \mathrm{L}$ of the P3TMA solution were solvent casted onto each side of the steel substrate, which was then allowed to dry under vacuum at room temperature for $24 \mathrm{~h}$. The weight of P3TMA deposited was determined as the difference between the masses of the coated and the uncoated working electrodes using a CPA26P Sartorius analytical microbalance with a precision of $10^{-6} \mathrm{~g}$. The exact amount of P3TMA covering the steel sheet was $6.4 \pm 0.4 \mathrm{mg}$. The reference electrode was an $\mathrm{Ag} \mid \mathrm{AgCl}$ electrode containing a $\mathrm{KCl}$ saturated aqueous solution $\left(\mathrm{E}^{\mathrm{o}}=0.222 \mathrm{~V}\right.$ at 25 ${ }^{\circ} \mathrm{C}$ ) and steel sheets were also used as counter electrodes. For statistical purposes, samples were run in triplicate for each current density tested. 
$\mathrm{FeCl}_{3}$ was used as the oxidant and dopant agent in the P3TMA polymerization reaction. Therefore, the counter ions neutralizing the positive charges in the polymer backbone are mostly $\mathrm{Cl}^{-}$or $\left[\mathrm{FeCl}_{4}\right]^{-}$anions. The doping level (DL), which is defined as the number of moles of anions per monomeric unit (MU) of $\mathrm{CP}$, was determined using the following expressions:

$$
\begin{aligned}
& D L=\frac{\operatorname{mols}\left(\mathrm{Cl}^{-}\right)}{\operatorname{mols}(\mathrm{MU})} \\
& \operatorname{mols}\left(\mathrm{Cl}^{-}\right)=\frac{\left|Q_{\text {red }}\right|}{F \cdot n}=\frac{\left|j_{\text {red }} \cdot t_{\text {red }}\right|}{F \cdot n} \\
& \operatorname{mols}(\mathrm{MU}) \approx \frac{m_{\mathrm{P} 3 \mathrm{TMA}}}{M W_{\mathrm{MU}}}
\end{aligned}
$$

where $Q_{r e d}$ is the reduction charge $(\mathrm{C}), j_{\text {red }}(\mathrm{A})$ is the current intensity applied, $t_{\text {red }}(\mathrm{s})$ is the reduction time, $\mathrm{F}$ is the Faraday constant $(\mathrm{C} / \mathrm{mol}), n$ is the electron charge involved in the electrochemical process $(n=1), m_{P 3 T M A}(\mathrm{~g})$ is P3TMA mass deposited onto each working electrode, and $M W_{M U}$ is the molecular weight of the monomeric unit of P3TMA $(\mathrm{g} / \mathrm{mol})$.

\section{Electrochemical characterization of PEU-co-PEA/P3TMA hybrid scaffolds}

In order to assess the electrochemical behavior of the PEU-co-PEA/P3TMA scaffolds cyclic voltammetry (CV) studies were conducted with an Autolab PGSTAT302N galvanostat equipped with the ECD module (Ecochimie, The Netherlands). Measurements were performed on fiber mats, which were deposited by electrospinning on both sides of steel AISI 316 sheets of $1 \mathrm{~cm}^{2}$. All electrochemical assays were performed using a three-electrode one compartment cell under nitrogen atmosphere and at room temperature.

The cell was filled with $50 \mathrm{~mL}$ of PBS solution containing $0.1 \mathrm{M} \mathrm{LiClO}_{4}$ as supporting electrolyte $(\mathrm{pH}=7.4)$. Steel AISI 316 sheets of $1 \times 1 \mathrm{~cm}^{2}$ were used as working and counter electrode while an $\mathrm{Ag} \mid \mathrm{AgCl}$ electrode containing $\mathrm{KCl}$ saturated aqueous solution was the

reference electrode (offset potential versus the standard hydrogen electrode, $\mathrm{E}^{0}=0.222 \mathrm{~V}$ at 
$25^{\circ} \mathrm{C}$ ). Ten cyclic voltammograms were registered in the potential range from -0.4 to $+1.1 \mathrm{~V}$ at a scan rate of $50 \mathrm{mV} / \mathrm{s}$.

The electroactivity, which indicates the ability to exchange charge reversibly, was evaluated by examining the similarity between the anodic and cathodic areas of the control voltammogram. The electrochemical stability (i.e. loss of electroactivity, LEA) was determined using the following expression:

$$
\operatorname{LEA}(\%)=\frac{\Delta Q}{Q_{1}} 100
$$

where $\Delta Q$ is the difference of anodic voltammetric charge between the first cycle and the last cycle and $Q_{1}$ is the anodic voltammetric charge corresponding to the first cycle.

\section{RESULTS AND DISCUSSION}

\section{Electrospinning of PEU-co-PEA}

Several solvents and binary solvent mixtures were tested at different voltages, flow rates, polymer concentrations and needle tip-collector distances to get continuous electrospun microfibers. PEU-co-PEA is soluble in most organic solvents (e.g., chloroform, methanol, ethanol and dimethylformamide), the best solubility being attained in a $\mathrm{CHCl}_{3}: \mathrm{MeOH} 10: 1 \mathrm{v} / \mathrm{v}$ mixture. Usually the electrospinning process requires relatively high polymer concentration to avoid the formation of droplets and electrospun beads. ${ }^{32}$ In this case, the minimum value needed to obtain continuous microfibers under a wide range of processing conditions was $18 \%$ $(w / v)$. In fact, the high molecular weight of the copolymer facilitated the electrospinning process and good fibers were obtained in most test conditions. Nevertheless, the applied voltage was essential to minimize the dramatic effect of the bead formation. This effect is illustrated in Figure 2, which compares fibers obtained under voltages of $25 \mathrm{kV}$ and $20 \mathrm{kV}$. Optimal processing conditions (i.e. those that avoid the formation of broken fibers and beads) 
are indicated in Table 1 while a representative SEM micrograph is given in Figure 3. Fibers are continuous and tortuous and, in general, have a smooth surface although striations (white arrow) and porous regions (red arrow) can also be detected. Analysis of the fibers diameter (Figure 3b) shows a unimodal distribution with an average value close to $2.63 \mu \mathrm{m}$.

\section{Phase separation of PEU-co-PEA/P3TMA mixtures}

PEU-co-PEA and P3TMA were independently dissolved in $\mathrm{CHCl}_{3}: \mathrm{MeOH}$ 10:1 v/v mixtures up to reach concentrations of $36 \%(w / v)$. Equal volumes of the two solutions were subsequently mixed in order to get a single solution with $18 \%(w / v)$ concentration of each polymer. The complex system (two solvents and two polymers) spontaneously evolved towards a phase separation with a dense and brown colored P3TMA rich phase (60 v-\%) and a lighter and yellowish PEU-co-PEA rich phase (Figure 4). The former corresponded to $60 v$ $\%$. This induced phase separation is expected to facilitate the preparation of CP-enriched fibers.

Polymer composition of each phase was ascertained by means of ${ }^{1} \mathrm{H}$ NMR spectra (Figure 5). P3TMA signals are predominant in the spectrum of the dense phase (Figure 5a). Specifically, signals of methylene and methyl lateral groups appear overlapped as a double duplet (3.82-3.80 ppm and 3.62-3.60 ppm) and a duplet (3.77 and $3.72 \mathrm{ppm})$, respectively. Splitting of these signals is interpreted as a consequence of the different arrangements of thiophene rings during chemical polymerization and the corresponding triad and dyad (e.g. head-to-head and head-to-tail) sensitivities. ${ }^{17,31}$ In addition, the spectrum shows also multiple peaks that can be easily assigned to the predominant PEU unit of the copolymer.

Composition was determined considering the area of the signal at 4.20-4.10 ppm $\left(\mathrm{O}-\mathrm{CH}_{2}\right.$ protons of the hexanediol unit of both PEA and PEU moieties) and the area of the above mentioned signals corresponding to the lateral groups of P3TMA:

$$
\text { PEU-co-PEA mol\% }=100 \times\left(\mathrm{A}_{4.20-4.10} / 4\right) /\left(\mathrm{A}_{4.20-4.10} / 4+\mathrm{A}_{3.82-3.60} / 5\right)(5)
$$


The spectrum of the light phase (Figure $5 \mathrm{~b}$ ) clearly shows predominant signals attributed to the biodegradable copolymer. In addition, the small peak at $2.62 \mathrm{ppm}$ associated to the $\mathrm{CO}-$ $\mathrm{CH}_{2}$ protons of the sebacoyl unit of the PEA moiety can also be appreciated. The spectrum recovered from the interphase evidences an intermediate composition, as it is deduced from the signals appearing in the 4.5-3.5 ppm region (inset of Figure 5b).

Molar percentage of PEU-co-PEA is 5.2, 33 and $61 \%$ for the dense, the interphase and the light phase, respectively. These values correspond to 10,50 and $76 \mathrm{wt}-\%$ when the molecular weight of the corresponding repeat units is considered. The global polymer concentration (i.e., PEU-co-PEA plus P3TMA) estimated from a simple mass balance is $24 \%$ and $54 \%(w / v)$ for the dense and light phases, respectively. These percentages were experimentally corroborated by weighting the residues recovered after solvent evaporation for each phase.

Figure 6 compares the FTIR spectra of the biodegradable PEU-co-PEA and the conducting P3TMA samples. The spectrum of the polymer mixture coming from the dense phase, which is also displayed, is practically identical to the P3TMA spectrum (i.e. peaks do not shift as a consequence of new intermolecular interactions). Specifically, bands at $2950-2840 \mathrm{~cm}^{-1}(\mathrm{CH}$ stretching), $1732 \mathrm{~cm}^{-1}(\mathrm{C}=\mathrm{O}), 1435 \mathrm{~cm}^{-1}$ (thiophene ring stretching), $1322 \mathrm{~cm}^{-1}$ (methyl deformation), 1198 and $1167 \mathrm{~cm}^{-1}$ (asymmetric and symmetric C-O stretching), $1012 \mathrm{~cm}^{-1}$, $839 \mathrm{~cm}^{-1}$ (aromatic $\mathrm{CH}$ out of plane deformation) and $741 \mathrm{~cm}^{-1}$ (methyl rocking) are characteristic of the P3TMA rich sample. The spectrum of PEA-co-PEU shows the typical $\mathrm{CH}_{2}\left(2955\right.$ and $\left.2871 \mathrm{~cm}^{-1}\right)$, hydrogen bonded $\mathrm{NH}$ (3339 and $\left.1558 \mathrm{~cm}^{-1}\right), \mathrm{C}=\mathrm{O}$ ester $\left(1734 \mathrm{~cm}^{-}\right.$ $\left.{ }^{1}\right), \mathrm{C}=\mathrm{O}$ urea $\left(1633 \mathrm{~cm}^{-1}\right)$ and $\mathrm{C}-\mathrm{O}$ ester $\left(1243\right.$ and $\left.1183 \mathrm{~cm}^{-1}\right)$ groups. Note that the absorption of the $\mathrm{C}=\mathrm{O}$ ester groups appeared at the same wavelength in all samples.

Figure 7 compares the GPC curves of the initial biodegradable and CPs and those recovered from the dense and light phases. P3TMA presents a narrow and unimodal distribution with a maximum at 14,400 g/mol. PEU-co-PEA shows a broader distribution and 
two peaks centered at 60,200 and $1015 \mathrm{~g} / \mathrm{mol}$. Although the peak corresponding to the lower molecular weight fraction is small, it has been used to evaluate the possible existence of fractionation processes during phase separation. This feature may occur if strong interactions can be established between P3TMA and the terminal groups of PEU-co-PEA. The chromatogram of the polymer coming from the light phase presents a predominant peak that corresponded to $60,200 \mathrm{~g} \mathrm{~mol}^{-1}$ and a long tail that should include both the P3TMA fraction and the low molecular weight copolymer fraction. The GPC curve of the polymer coming from the dense phase is very broad and corresponds to a low molecular weight, as expected from a P3TMA rich fraction. Deconvolution of the curve allowed us to observe two additional peaks associated to PEU-co-PEA (Figure 7b). It is interesting to note that the low molecular fraction of the copolymer is detected in both dense and light phases, allowing us to discard a significant molecular weight fractionation.

\section{P3TMA doping level}

Electrochemical assays were performed to assess the doping level (DL) of as-synthesized P3TMA, which in fact may also be useful to evaluate the capability to form intermolecular interactions with charged low molecular weight oligomers. Figure 8 displays a representative chronopotenciometry curve of P3TMA submitted to a reduction process under a constant cathodic current intensity of $-2 \mathrm{~mA}$. Although other current intensities of growing values from $-0.1 \mathrm{~mA}$ to $-2 \mathrm{~mA}$ were tested, only samples reduced at $-2 \mathrm{~mA}$ resulted in a complete dedoping of the CP.

The curve shows that the system potential is gradually decreasing to more negative values, which is indicative of a dedoping process. The potential value rapidly reduces before stabilizing shortly at around 500 seconds. Interestingly, the system potential starts to increase towards more positive values at $t_{\text {red }}=601.5$ seconds (inset of Figure 8). Therefore, the reduction charge applied up to that minimum equals $-1.203 \mathrm{C}$. This response is interpreted as 
the completion of the dedoping process. The electrochemical process has reduced completely the polymer backbone closing the polymer structure up to a point that results in the film break. These fractured regions expose the steel support surface and open new paths for the intensity to flow easily. Thus, the DL determination reveals that each monomeric unit of P3TMA contains $0.27 \pm 0.01$ counterions (one positive hole per 3.7 thiophene rings), which corresponds to 6.0 wt. $\% \pm 0.29$ wt. $\%$ of $\mathrm{Cl}^{-}$counterions in as-synthesized P3TMA samples. This DL is in good agreement with those determined for other CPs. ${ }^{33-35}$ Aradilla et al. ${ }^{33}$ prepared poly[1-(2-cyanoethyl)pyrrole in acetonitrile using $\mathrm{LiClO}_{4}$ as dopant agent while Gök et al. ${ }^{34}$ synthesized polythiophene in chloroform using $\mathrm{FeCl}_{3}$ as oxidant. In both cases it was stated that because of structural disorders in the $\mathrm{CP}$ chains and crosslinking, one positive charge is generated per approximately three monomeric units, the measured DLs being $0.35^{33}$ and $0.33 .{ }^{34}$ In an earlier work, ${ }^{35}$ a reaction of 2,2-bithiophene with copper(II) perchlorate in acetonitrile was conducted and yielded polymers with a DL of $\sim 0.17$.

For CPs, such as polythiophene and its derivatives, the DL and the extension of the $\pi$ conjugated system along the polymer backbone are closely related with their electronic properties. ${ }^{36}$ The conductivity increases with the amount of dopant until a saturation limit is reached. Comparative studies of polyalkythiophenes doped with different agents showed that materials doped with $\mathrm{FeCl}_{3}$ presented higher stability in comparison with others dopants. However, even for the doping saturation (i.e. one charge per thiophene monomeric unit), the conductivity of substituted polythiophene derivatives is around $10^{-6} \mathrm{~S} / \mathrm{cm}^{36}$

In a previous work, the electronic and electric response of nanomembranes prepared by using a spin-coated mixture of P3TMA and thermoplastic polyurethane (TPU) were exhaustively examined by UV-vis spectroscopy, conductive AFM and current/voltage measurements. ${ }^{37}$ Both TPU:P3TMA and P3TMA nanomembranes showed semiconductor behavior with very similar band gap energy values (2.35 and $2.32 \mathrm{eV}$, respectively). In 
addition, current and conductivity values determined for the composite nanomembranes at P3TMA-rich domains ranged from 0.43 to $1.85 \mathrm{pA}$ and from $2.23 \times 10^{-5}$ to $5.19 \times 10^{-6} \mathrm{~S} / \mathrm{cm}$, respectively.

\section{Electrospinning of the dense PEU-co-PEA/P3TMA phase mixture}

Electrospinning process was optimized again for the dense phase since polymer composition was modified and also the total polymer concentration varied considerably (i.e. from $36 \% w / v$ to $24 \% w / v)$. It should be pointed out that the presence of a small fraction of PEU-co-PEA is essential since electrospinning of P3TMA alone was unfeasible, even at so high concentration, since its low molecular weight leads to abundant drop formation.

Figure 9 is an example of the optimization process for a given tip-collector distance followed by optical microscopy observation. Although beads and broken fibers were attained in most test conditions (Table 1), the increase of the flow rate up to $3.5 \mathrm{~mL} / \mathrm{h}$ and the applied potential to $25 \mathrm{kV}$ allowed us to get homogeneous and continuous microfibers. SEM images (Figure 10a) reveal a smooth surface texture, beads and broken fibers being relatively infrequent. The average diameter (Figure 10b) is close to $1.47 \mu \mathrm{m}$ but values extended over a relatively wide range (from $500 \mathrm{~nm}$ to $2.50 \mu \mathrm{m}$ ). The hybrid fibers are clearly less tortuous than those prepared from PEU-co-PEA and have also a significant lower diameter $(1.47 \mu \mathrm{m}$ respect to $2.63 \mu \mathrm{m})$. Although the latter observation is consistent with the decrease on the global polymer concentration in the electrospinable solution (i.e. from $36 \% w / v$ to $24 \% w / v$ ), the increase in the flow rate (i.e. from $1.5 \mathrm{~mL} / \mathrm{h}$ to $3.5 \mathrm{~mL} / \mathrm{h}$ ) points out to the opposite behavior.

\section{Physicochemical characterization of PEU-co-PEA/P3TMA electrospun scaffolds}

Figure 11 compares the heating run of the electrospun hybrid scaffold, the electrospun PEU-co-PEA scaffold and the P3TMA powder sample. P3TMA derived from chemical 
polymerization is semicrystalline despite the random disposition of its repeating unit and consequently a small melting peak at $110.9^{\circ} \mathrm{C}$ can be observed. Nevertheless, the sample has a high amorphous content since a clear glass transition is detected at $68.7^{\circ} \mathrm{C}$. The electrospun PEU-co-PEA scaffold is amorphous and renders only a clear glass transition at a lower temperature (i.e. $41.9^{\circ} \mathrm{C}$ ) due the increased chain flexibility. The incorporation of a small percentage of PEA units affects its crystallinity since the parent 1L6 PEU was reported to be semicrystalline. ${ }^{25}$ In addition, it should be pointed out that the applied electrical potential tends to induce molecular orientation and probably favors crystallization. ${ }^{38,39}$ However, this effect is clearly insufficient for PEU-co-PEA, the sample remaining amorphous after electrospinning.

Typical relaxation endothermic peaks are detected for both P3TMA and PEU-co-PEA samples, indicating that metastable equilibrium thermodynamic conditions with a lower specific volume, enthalpy and entropy are achieved in the glassy state. The PEU-coPEA/P3TMA electrospun scaffold shows a complex thermal behaviour with different endothermic peaks. Thus, two relaxation peaks at 58.7 and $70.1{ }^{\circ} \mathrm{C}$ can be detected and, therefore, the presence of two amorphous phases is inferred. The greatest change on the specific heat capacity corresponds to the transition that occurred at a temperature intermediate between those observed for P3TMA and PEU-co-PEA. Hence, this transition can be associated to a miscible phase where both polymers were present. The second phase can only be associated to P3TMA since the transition is detected at practically the same temperature found for the conducting sample. Composition of the miscible phase was determined by considering the $T_{g}$ value predicted by the Fox equation: ${ }^{40}$

$$
1 / T_{g}=w_{1} / T_{g 1}+w_{2} / T_{g 2}
$$

where $w_{i}$ and $T_{g i}$ represent the weight fraction and the glass transition temperature of each component, respectively, and $T_{g}$ the glass transition temperature of the miscible phase. 
The miscible phase was composed of $35 \%$ of the copolymer and represented a $28.6 \%$ of the global sample as it can be deduced taking into account the global composition determined by NMR and assuming that the crystalline phase was negligible.

The X-ray diffraction profile of the PEU-co-PEA/P3TMA electrospun scaffold (Figure 12) reveals a practically amorphous character although some minor crystalline reflections could be detected. Note that the DSC heating run is complex and that melting and recrystallization peaks can be guessed. Basically the X-ray diffraction profile shows the typical reflections of P3TMA (e.g. a strong and well defined peak at $1.17 \mathrm{~nm}$ that is related to the interchain distance $^{17}$ ), amorphous halos and also some incipient signals that correspond to the reflections detected for the PEU-co-PEA powder sample (see blue dashed lines in Figure 12).

PEU-co-PEA/P3TMA scaffolds were thermally stable up to more than $200{ }^{\circ} \mathrm{C}$, as it is deduced from TGA and DTGA curves (Figure 13). The decomposition of this hybrid sample is different from those of the biodegradable and conducting components and, specifically, the degradation process is slightly enhanced. Thus, the biodegradable PEU-co-PEA sample displays a two-step degradation process with DTGA peaks at 310 and $360{ }^{\circ} \mathrm{C}$, which reflect the complex constitution of the repeat unit. The polymer is completely degraded at a temperature of $500{ }^{\circ} \mathrm{C}$. On the contrary, P3TMA gives rise to a char yield of $60 \%$ at $550{ }^{\circ} \mathrm{C}$ and degrades also following a two-step process with a predominant DTGA peak at $440{ }^{\circ} \mathrm{C}$.

The hybrid scaffold gives rise to a remarkable char yield at $550{ }^{\circ} \mathrm{C}$ (i.e. $50 \%$ ) that is consistent with its high P3TMA content. Nevertheless, the decomposition shows an unexpected behaviour since the first DTGA peak appears at $260{ }^{\circ} \mathrm{C}$, which is lower than the temperature observed for the first peak of the two components. Thus, the presence of P3TMA has a slightly negative influence on the thermal stability of the copolymer. Degradation of the hybrid scaffold finishes at lower temperature than that observed for the P3TMA sample (i.e. DTGA peaks at $360{ }^{\circ} \mathrm{C}$ and $440{ }^{\circ} \mathrm{C}$ ), due to the accelerated decomposition process caused by 
the previous decomposition of the PEU-co-PEA component. In summary, the incorporation of a small amount of the copolymer sample has a negative influence on the thermal stability of P3TMA but this feature is not essential to discard the use of the new scaffold at reasonable high temperatures.

\section{Electrochemical characterization of PEU-co-PEA/P3TMA electrospun scaffolds}

Figure 14a compares the first control voltammogram in PBS with $0.1 \mathrm{M} \mathrm{LiClO}_{4}$ of PEUco-PEA/P3TMA electrospun scaffolds having 90 and 24 wt- $\%$ of the CP, which were obtained from the dense and light phases, respectively. The voltammogram of the hybrid with 90 wt- $\%$ of P3TMA shows an oxidation process $O_{1}$ that begins at $0.55 \mathrm{~V}$ and an oxidation peak $\mathrm{O}_{2}$, indicating the formation of both polarons and bipolarons in the $\mathrm{CP}$ chains. The anodic peak potential of $O_{1}$ is $E_{p}^{a}\left(O_{1}\right)=0.81 \mathrm{~V}$ while $O_{2}$ is expected to reach an anodic peak potential at $E_{p}^{a}\left(O_{2}\right) \approx 1.3 \mathrm{~V}$ (i.e. $\sim 0.2 \mathrm{~V}$ above the reversal potential). On the other hand, the cathodic scan shows a weak reduction peak, $R_{1}$, with cathodic reduction potential $E_{p}^{c}\left(R_{1}\right)=$ $0.21 \mathrm{~V}$, which reflects that the $O_{1}$ and $O_{2}$ oxidation processes are highly irreversible. Similarly, the control voltammogram recorded for the hybrid having 24 wt- $\%$ of P3TMA presents two oxidation processes with $E_{p}^{a}\left(O_{1}\right)=0.90 \mathrm{~V}$ and $E_{p}^{a}\left(\mathrm{O}_{2}\right)$ higher than $1.10 \mathrm{~V}$. Moreover, the reduction peak is identified at $E_{p}^{c}\left(R_{1}\right)=0.12 \mathrm{~V}$. It is worth noting that the voltammograms recorded for the two hybrid scaffolds resemble that recently recorded for individual P3TMA using the same experimental conditions. ${ }^{15}$ The voltammogram of the sample without P3TMA, which is included in Figure 14a, shows a weak oxidation shoulder $O_{1}$ with anodic peak potential $E_{p}^{a}\left(O_{1}\right)=0.91 \mathrm{~V}$ while no reduction peak is detected at a cathodic reduction potential. Accordingly, the electrochemical activity of PEU-co-PEA electrospun scaffolds is consistent with the formation of charged species at unspecified 
positions, representing a significant difference with respect to PEU-co-PEA/P3TMA scaffolds in which polarons and bipolarons are formed at preferred positions. Current densities $(j)$ determined at $1.10 \mathrm{~V}$ were $0.11,0.44$ and $0.51 \mathrm{~mA} / \mathrm{cm}^{2}$ for samples containing 0,24 and 90 wt-\% of P3TMA, respectively. A similar behavior was recently observed in free-standing nanomembranes made of thermoplastic polyurethane and P3TMA mixtures, where TPU also showed some unspecific electrochemical activity. ${ }^{29}$

The electroactivity, which increases with the similarity between the anodic and cathodic areas, was determined using the voltammograms displayed in Figure 14a. Results indicate that the ability to store charge increases upon the addition of P3TMA. Specifically, the anodic charge of hybrid scaffolds having a 24 and $90 \mathrm{wt}-\%$ of the $\mathrm{CP}$ is $2.05 \mathrm{mC} / \mathrm{cm}^{2}$ and 3.08 $\mathrm{mC} / \mathrm{cm}^{2}$, respectively, while that of PEU-co-PEA scaffold decreases to $0.37 \mathrm{mC} / \mathrm{cm}^{2}$.

Figure $14 \mathrm{~b}$ represents the cyclic voltammograms recorded for the two hybrids and PEU-coPEA electrospun scaffolds after 10 consecutive oxidation-reduction cycles. The reduction of the areas associated to the cathodic and anodic scans with respect to the control voltammograms displayed in Figure 14a indicates that the ability to exchange charge reversibly decreases with the number of redox processes. This loss of electroactivity is typically related with the structural changes provoked by the redox processes in the $\mathrm{CP} .{ }^{41}$ Thus, the compactness of P3TMA increases with the number of redox cycles, hindering the access and scape of dopant ions during the oxidation and reduction processes, respectively. The LEA measured after 10 redox cycles for the PEU-co-PEA scaffolds is $46 \%$, decreasing to $39 \%$ and $24 \%$ for the hybrids with 24 and 90 wt- $\%$ of P3TMA. These values clearly indicate that electrochemical stability increases with the P3TMA content.

The overall of the electrochemical results indicate that the electroactivity and electrostability of electrospun microfibers made of P3TMA supported on biodegradable PEUco-PEA are similar to those reported for isolated P3TMA. ${ }^{15}$ As it was expected, the 
electrochemical response of these hybrid scaffolds improve with the P3TMA content. This feature combined with the fact that such $\mathrm{CP}$ behaves as a bioactive matrix ${ }^{14-17,29}$ support that PEU-co-PEA/P3TMA electrospun microfibers are promising candidate for biotechnological and biomedical applications.

\section{CONCLUSIONS}

Electrospun scaffolds having a high content of poly(3-thiophene methyl acetate) as a $\mathrm{CP}$ have been successfully prepared using a novel poly(ester urea) as a carrier. This should contribute to specific properties like biocompatibility and biodegradability, leading to a material with clear advantages for the biomedical field. The designed poly(ester urea) contains $\alpha$-amino acid units (L-leucine) and a small ratio of amide groups in a random disposition to improve solubility in organic solvents, which is an essential requirement for the electrospinning technique.

The selected biodegradable polymer can be easily electrospun over a wide range of conditions giving rise to homogeneous and continuous microfibers. These good properties guarantee the electrospinability of the low molecular weight P3TMA by the addition of a small percentage of PEU-co-PEA and specifically the preparation of electrospun scaffolds with a 90 wt-\% of CP.

Hybrid microfibers are continuous and show lower diameters than those prepared from the degradable polymer, which have been attributed to the formation of strong intermolecular interactions. In fact, as prepared P3TMA revealed exceptional doping level characteristics since each monomeric unit was able to interact with 0.27 counterions. Thermal analyses have indicated that microfibers present a phase in which conducting and biodegradable polymers are well-mixed. Physicochemical characterization of the hybrid scaffolds has revealed a low crystallinity, a high thermal stability and a remarkable electrochemical response. The 
formation of charged species at specific positions, the electroactivity and the electrochemical stability of PEU-co-PEA/P3TMA hybrid scaffolds are very similar to those of as prepared P3TMA.

\section{ACKNOWLEDGEMENTS}

Authors are in debt to supports from MINECO and FEDER (MAT2012-34498 and MAT2012-36205) and Generalitat de Catalunya (2009SGR925, 2009SGR1208 and XRQTC). M.M.P.-M. thanks financial support through a FPI-UPC grant. 


\section{REFERENCES}

1. B. Guo, L. Glavas and A. C. Albertsson, Prog, Polym. Sci., 2013, 38, 1263-1286.

2. E. Llorens, E. Armelin, M.M. Pérez-Madrigal, L. J. del Valle, C. Alemán and J. Puiggalí, Polymers, 2013, 5, 1115-1157.

3. A. D. Bendrea, L. Cianga and I. Cianga, J. Biomater. Appl., 2011, 26, 3-84.

4. Y. Guo, M. Y. Li, A. Mylonakis, J. J. Han, A. G. MacDiarmid, X. S. Chen, P. I. Lelkes and Y. Wei, Biomacromolecules, 2007, 8, 3025-3034.

5. Y. Liu, J. Hu, X. Zhuang, P. Zhang, X. Chen, Y. Wei and X. Wang, Macromol. Biosci., $2011,11,806-813$.

6. H. H. Kuhn and A. D. Child, Electrically Conducting Textiles. Handbook of Conducting Polymers, 2nd ed.; T. A. Skotheim, R. L. Elsenaumer and J. R. Reynolds, Eds.; Marcel Dekker: New York, NY, USA, 1998; pp. 993-1104.

7. S. Nair, S. Natarajan and S. H. Kim, Macromol. Rapid Commun., 2005, 26, 1599-1603.

8. S. Aznar-Cervantes, M. I. Roca, J. G. Martinez, L. Meseguer-Olmo, J. L. Cenis, J. M. Moraleda and T. F. Otero, Biochemistry, 2012, 85, 36-43.

9. M. Li, Y. Guo, Y. Wei, A. G. MacDiarmid and P. I. Lelkes, Biomaterials, 2006, 27, 27052715.

10. D. Kai, M. P. Prabhakaran, G. Jin and S. Ramakrishna, J. Biomed. Mater. Res. A, 2011, 99, 376-385.

11. C. Sharma, S. Gautam, A. K. Dinda and N. C. Mishra, Adv. Mater. Lett., 2011, 2, 90-99.

12. H. Liu, C. H. Reccius and H. G. Craighead, Appl. Phys. Lett., 2005, 87, 253106:1253106:3.

13. S. Lee, G. D. Moon and U. Jeong, U. J. Mater. Chem., 2009, 19, 743-748. 
14. E. Armelin, A.L. Gomes, M.M. Pérez-Madrigal, J. Puiggalí, L. Franco, L.J. del Valle, A. Rodríguez-Galán, J.S. de C. Campos, N. Ferrer-Anglada and C. Alemán, J. Mater. Chem., 2012, 22, 585-594.

15. M. M. Pérez-Madrigal, E. Armelin, L.J. del Valle, F. Estrany and C. Alemán, Polym. Chem., 2012, 3, 979-991.

16. M. M. Pérez Madrigal, M. I. Giannotti, G. Oncins, L. Franco, E. Armelin, J. Puiggalí, F. Sanz, L. J. del Valle and C. Alemán, Polym. Chem., 2013, 4, 568-583.

17. E. Llorens, M. M. Pérez-Madrigal, E. Armelin, L. J. del Valle, J. Puiggalí and C. Alemán, RCS Adv. 2014, 4, 15245-15255.

18. R. Katsarava and Z. Gomurashvili, Biodegradable Polymers composed of naturally occurring $\alpha$-amino acids. In Handbook of Biodegradable Polymers - Isolation, Synthesis, Characterization and Applications; A. Lendlein and A. Sisson, Eds.; Wiley-VCH, Verlag GmbH \& Co. KGaA. 2011; Chapter 5, p. 107.

19. M. Okada, Progr. Polym. Sci., 2000, 27, 87-133.

20. P. A. M. Lips and P. J. Dijkstra, Biodegradable polyesteramides. In Biodegradable Polymers for Industrial Applications; R. Smith, Ed.; CRC Press, Boca Raton, 2005; Chapter 5, pp. 109-139.

21. A. Rodríguez-Galán, L. Franco and J. Puiggalí, Polymers, 2011, 3, 65-99.

22. S. K. Murase and J. Puiggalí, Poly(Ester Amide)s: Recent Developments on Synthesis and Applications. In Natural and synthetic biomedical polymers; S. G. Kumbar, C. T. Laurencin and M. Deng, Eds.; Elsevier: Burlington-San Diego, USA, 2014. Chapter 8, pp. 145-163.

23. A. Diaz, R. Katsarava and J. Puiggalí, Int. J. Mol. Sci., 2014, 15, 7064-7123.

24. T. Kartvelishvili, G. Tsitlanadze, L. Edilashvili, N. Japaridze and R. Katsarava, Macromol. Chem. Phys., 1997, 198, 1921-1932. 
25. Z. D. Gomurashvili, R. Katsarava and D. Tugushi, Poly(ester urea) polymers and methods of use. WO 2007050415 A2. 3 May 2007.

26. A. Díaz, L. J. del Valle, D. Tugushi, R. Katsarava and J. Puiggalí. Submitted work.

27. K. S. Stakleff, F. Lin , L. A. Smith Callahan, M. B. Wade, A. Esterle, J. Miller, M. Graham and M. L. Becker, Acta Biomater., 2013, 9, 5132-5142.

28. J. Yu, F. Lin, P. Lin, Y. Gao and M. L. Becker, Macromolecules, 2014, 47, 121-129.

29. M. M. Pérez-Madrigal, M. I. Giannotti, L. J. del Valle, L. Franco, E. Armelin, J. Puiggalí, F. Sanz and C. Alemán, ACS Appl. Mater. Interfaces, 2014, 6, 9719-9732.

30. R. Katsarava, V. Beridze, N. Arabuli, D. Kharadze, C. C. Chu and C. Y. Wen, J. Polym. Sci. Part A: Polym. Chem., 1999, 37, 391-407.

31. B. Kim. L. Chen, J. Gong and Y. Osada, Macromolecules, 1999, 32, 3964-3969.

32. C. J. Luo, M. Nangrejo and M. Edirisinghe, Polymer, 2010, 51, 1654-1662.

33. D. Aradilla, F. Estrany, E. Armelin, R. Oliver, J. I. Iribarren and C. Alemán, Macromol. Chem. Phys., 2010, 211, 1663-1672.

34. A. Gök, M. Omastová and A. G. Yavuz, Synth. Met., 2007, 157, $23-29$.

35. M. B. Inoue, E. F. Velazquez and M. Inoue, Synth. Met., 1988, 24, 223-229.

36. D. Fichou, D., Handbook of oligo- and polythiophenes; Wiley-VCH: Weinheim ; New York, 1999; p 534.

37. M. M. Pérez-Madrigal, M. I. Giannotti, E. Armelin, F. Sanz and C. Aleman, Polym. Chem., 2014, 5, 1248-1257.

38. J. Zeng, X. Chen, Q. Liang, X. Xu and X. Ping, Macromol. Biosci., 2004, 4, 1118-1125.

39. L. J. del Valle, R. Camps, A. Díaz, L. Franco, A. Rodríguez-Galán and J. Puiggalí J. Polym. Res. 2011, 18, 1903-1917.

40. T. G. Fox., Bull. Am. Phys. Soc., 1956, 1, 123-128.

41. D. Aradilla, F. Estrany and C. Alemán, C. J. Phys. Chem. C, 2011, 115, 8430-8438 


\section{FIGURE CAPTIONS}

Figure 1. a) Synthesis of the biodegradable 1L693-8L67 PEU-co-PEA. b) Chemical structure of the P3TMA conducting polymer.

Figure 2. Optical micrographs of $1 \mathrm{~L} 6_{93}-8 \mathrm{~L}_{7}$ PEU-co-PEA electrospun microfibers obtained at a flow rate of $1.5 \mathrm{~mL} / \mathrm{h}$, needle tip-collector distance of $24 \mathrm{~cm}$ and applied voltages of 20 $\mathrm{kV}$ (a) and $25 \mathrm{kV}(\mathrm{b})$.

Figure 3. (a) SEM micrograph of $1 \mathrm{~L} 6_{93}-8 \mathrm{~L} 6_{7}$ PEU-co-PEA electrospun microfibers obtained under optimized processing conditions. Striations and pores are indicated by white and red arrows, respectively. (b) Diameter distribution of the above indicated microfibers.

Figure 4. Image showing the spontaneous phase separation produced by mixing equal volumes of $36 \%(w / v)$ solutions of $1 \mathrm{L6}_{93}-8 \mathrm{~L}_{7}$ and P3TMA in $\mathrm{CHCl}_{3}: \mathrm{MeOH}$ 10:1 v/v and the resulting macroscopic textures obtained after the electrospinning of each phase.

Figure 5. ${ }^{1} \mathrm{H}$ NMR spectra of the PEU-co-PEA/P3TMA mixture obtained from the dense (P3TMA-enriched) brown phase (a) and the light yellowish phase (b). The inset shows the 4.5-3.5 ppm region of the interphase.

Figure 6. FTIR spectra of $1 \mathrm{~L} 6_{93}-8 \mathrm{~L}_{7}$ PEU-co-PEA (a), the PEU-co-PEA/P3TMA mixture from the dense phase (b) and P3TMA (c). The inset corresponds to a magnification for signals corresponding to $\mathrm{CH}_{2}$ and $\mathrm{CH}_{3}$ stretching vibrations. Red dashed lines point out common signal for the three samples, whereas black and blue dashed lines indicate common signals between the mixture and PEU-co-PEA and P3TMA, respectively.

Figure 7. a) GPC chromatograms of $1 \mathrm{~L}_{93}-8 \mathrm{~L}_{7}$ PEU-co-PEA (orange), P3TMA (garnet) and polymer mixtures from dense (green) and light (blue) phases. b) Deconvolution of the GPC 
curve of the dense phase (green) into typical curves of P3TMA (red) and 1L6 ${ }_{93}-8 \mathrm{L6}_{7}$ PEU-coPEA (orange). The addition of deconvoluted profiles corresponds to the gray curve.

Figure 8. Chronopotenciometry curve for P3TMA submitted to an electrochemical reduction process at $-2 \mathrm{~mA}$.

Figure 9. Optical micrographs showing the optimization sequence for the electrospinning parameters and typical morphologies produced by electrospinning the dense phase obtained from the spontaneous separation of $36 \%(w / v)$ solution of 1 L6 $693_{93}-8 \mathrm{~L}_{7}$ PEU-co-PEA plus P3TMA in $\mathrm{CHCl}_{3}: \mathrm{MeOH}$ 10:1 v/v: a) highly broken fibers, b) fibers with beads, and c) continuous fibers. The systematic optimization procedure is described in Table 1.

Figure 10. (a) SEM micrograph of electrospun microfibers derived from the P3TMA rich phase under optimized processing conditions. (b) Diameter distribution of the above indicated microfibers.

Figure 11. DSC $1^{\text {st }}$ heating scans performed with $1 \mathrm{~L} 6_{93}-8 \mathrm{~L} 6_{7}$ PEU-co-PEA electrospun scaffold (a), PEU-co-PEA/P3TMA electrospun scaffold (b) and P3TMA powder sample (c). Dashed red arrows point out endothermic processes detected for 1L6 ${ }_{93}-8 \mathrm{~L} 6_{7} / \mathrm{P} 3 \mathrm{TMA}$ electrospun scaffold. Solid red arrows point out the low temperature relaxation peak observed in $1 \mathrm{~L} 6_{93}-8 \mathrm{~L}_{7}$ PEU-co-PEA and PEU-co-PEA /P3TMA electrospun scaffolds. The dashed black line related the relaxation peaks associated to P3TMA.

Figure 12. X-Ray powder diffractograms of the $1 \mathrm{~L}_{93}-8 \mathrm{~L} 6_{7}$ PEU-co-PEA powder sample, PEU-co-PEA /P3TMA electrospun scaffold and P3TMA powder sample. Blue and red dashed lines point out typical reflections of the biodegradable copolymer and the conducting polymer, respectively. 
Figure 13. TGA degradation curves of $1 \mathrm{~L} 6_{93}-8 \mathrm{~L}_{7}$ PEU-co-PEA electrospun scaffold (solid line), PEU-co-PEA /P3TMA electrospun scaffold (dotted line) and P3TMA powder sample (dashed line). Inset compares DTGA curves of the indicated samples.

Figure 14. Cyclic voltammograms for $1 \mathrm{~L}_{93}-8 \mathrm{~L}_{7}$ PEU-co-PEA (purple line) and PEU-coPEA /P3TMA electrospun scaffolds having 24 wt- $\%$ (blue line) and 90\% wt-\% (black line) of conducting polymer in PBS with $0.1 \mathrm{M} \mathrm{LiClO}_{4}$ : (a) first control voltammogram; and (b) voltammogram after 10 consecutive oxidation-reduction cycles. Initial and final potential: $0.40 \mathrm{~V}$; reversal potential: $1.10 \mathrm{~V}$. Scan rate: $50 \mathrm{mV} / \mathrm{s}$. 
Table 1. Optimization of the electrospinning conditions. ${ }^{\text {a }}$ Both the voltage and rate conditions are optimized to avoid the presence of broken fibers and beads.

\begin{tabular}{cccc}
\hline Sample $^{\text {b }}$ & $\begin{array}{c}\text { Voltage } \\
(\mathbf{k V})\end{array}$ & $\begin{array}{c}\text { Rate } \\
(\mathbf{m L} / \mathbf{h})\end{array}$ & Morphological characteristics \\
\hline PEU-co-PEA/P3TMA 100 & 20 & 1.5 & Fibers with beads \\
& $\mathbf{2 5}$ & $\mathbf{1 . 5}$ & Homogeneous fibers \\
PEU-co-PEA/P3TMA 10 & 20 & 1.0 & Highly broken fibers with beads \\
& 20 & 1.5 & Broken fibers with beads \\
& 25 & 1.5 & Broken fibers with beads \\
& 15 & 2.5 & Broken fibers with beads \\
& 20 & 2.5 & Broken fibers with beads \\
& 20 & 3.5 & Slightly broken fibers with beads \\
& $\mathbf{2 5}$ & $\mathbf{3 . 5}$ & Continuous fibers \\
\hline
\end{tabular}

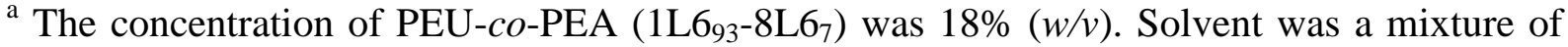
$\mathrm{CHCl}_{3} / \mathrm{MeOH}(10: 1, v / v)$. The optimal parameters are indicated in bold characters. In all cases, the optimal distance between syringe tip and collector was $24 \mathrm{~cm}$. ${ }^{\mathrm{b}}$ The number after abbreviatures indicates the $w t-\%$ of the PEU-co-PEA component in the mixture. 
a)

$2 \mathrm{NH}_{2} \mathrm{CH}\left(\mathrm{CH}_{2} \mathrm{CH}\left(\mathrm{CH}_{3}\right)_{2}\right) \mathrm{COOH}+\mathrm{HO}\left(\mathrm{CH}_{2}\right)_{6} \mathrm{OH}$

$\downarrow \begin{gathered}\mathrm{CH}_{3} \mathrm{C}_{6} \mathrm{H}_{4} \mathrm{SO}_{3} \mathrm{H} \\ (\mathrm{TsOH})\end{gathered}$

TsO- ${ }^{-} \mathrm{NH}_{3} \mathrm{CH}\left(\mathrm{CH}_{2} \mathrm{CH}\left(\mathrm{CH}_{3}\right)_{2}\right) \mathrm{CO}-\mathrm{O}\left(\mathrm{CH}_{2}\right)_{6} \mathrm{O}-\mathrm{COCH}\left(\mathrm{CH}_{2} \mathrm{CH}\left(\mathrm{CH}_{3}\right)_{2}\right) \mathrm{NH}_{3}{ }^{+} \mathrm{OTs}$

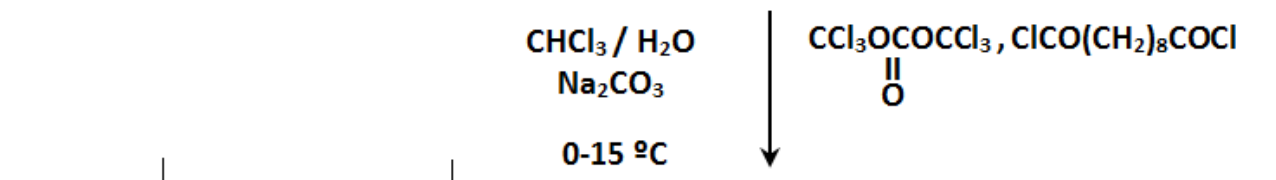

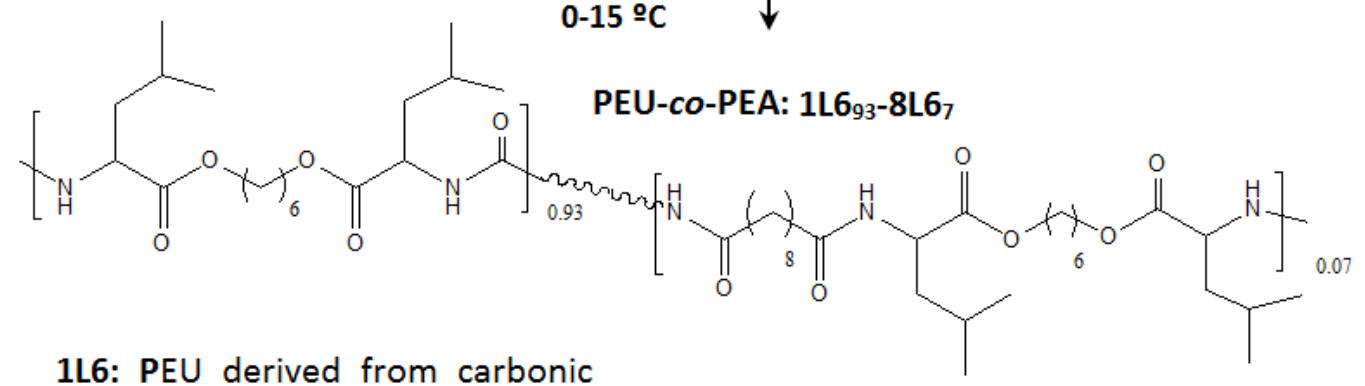
acid (1) L-Leucine (L) and 1,6hexanediol (6)
8L6: PEA derived from sebacic acid (8), L-Leucine (L) and 1,6-hexanediol (6) b)

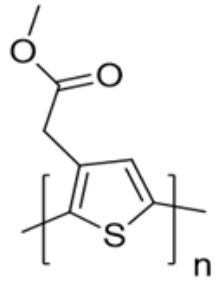

P3TMA

Figure 1 

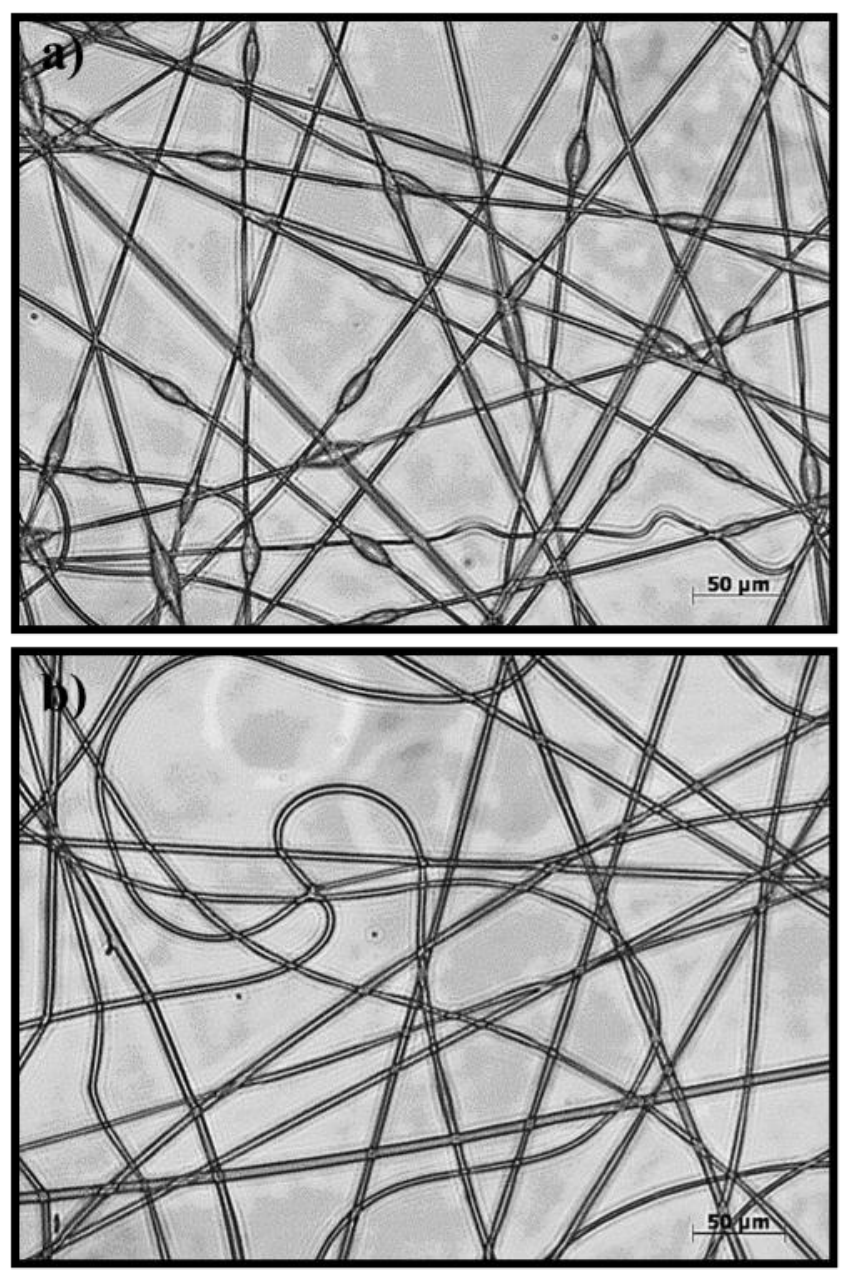

Figure 2 

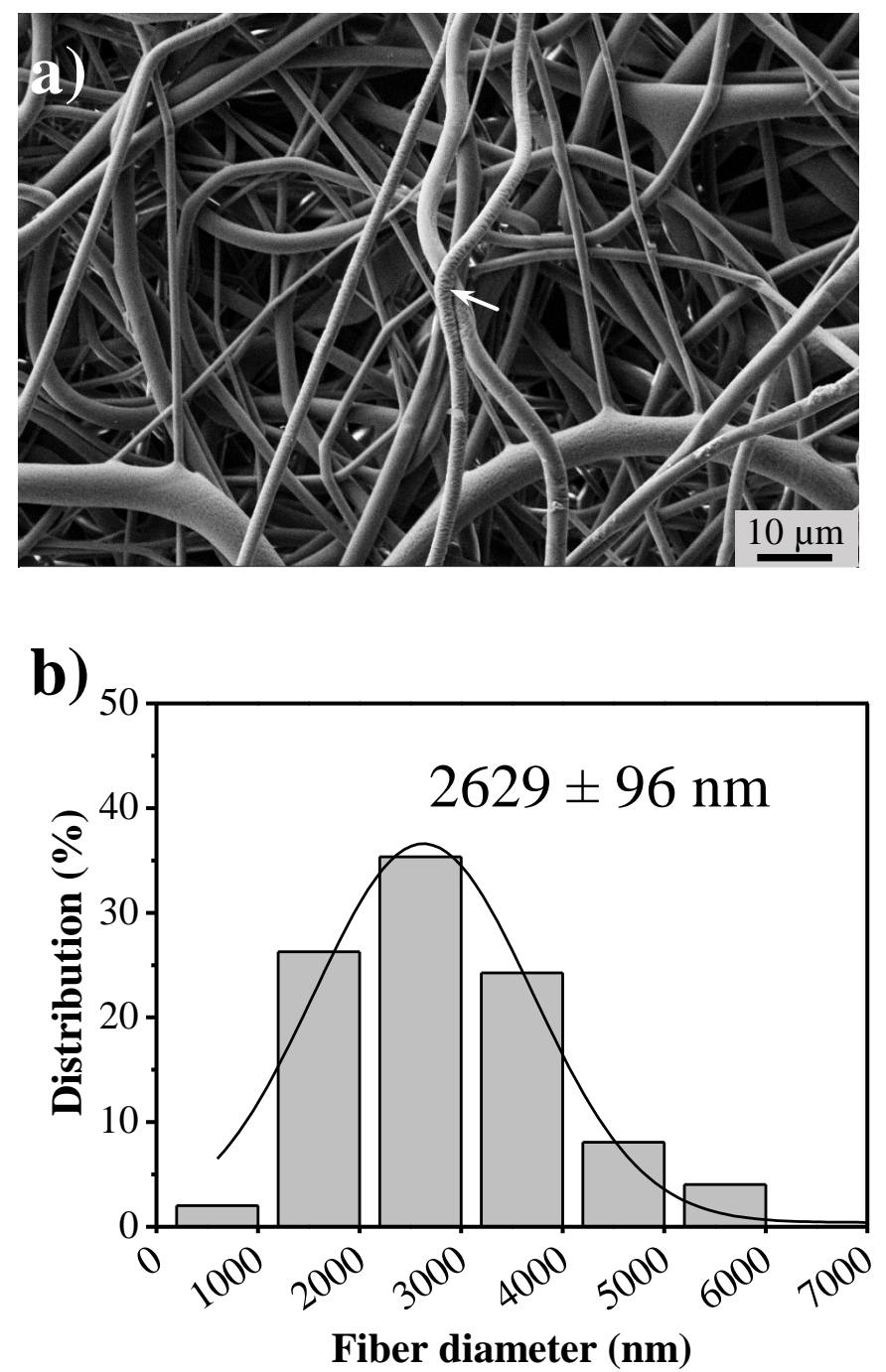

Figure 3 


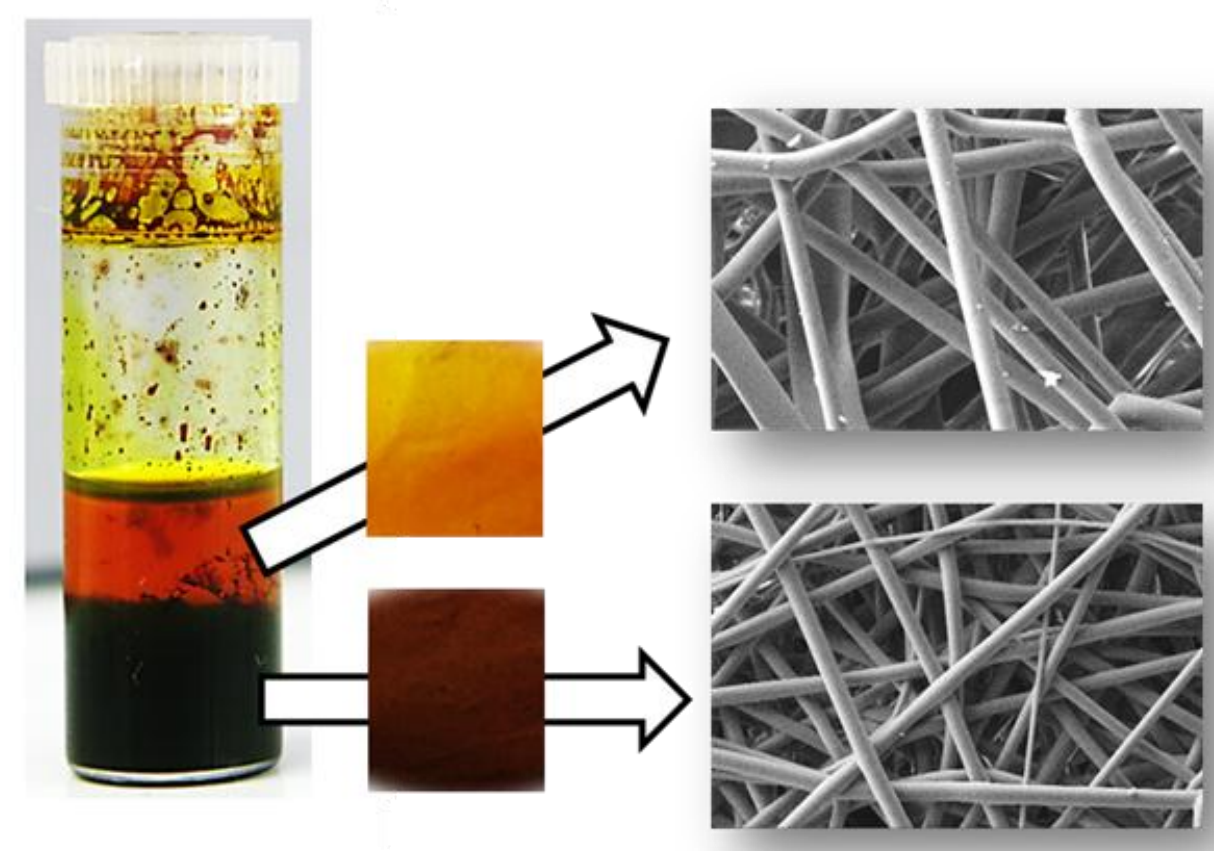

Figure 4 

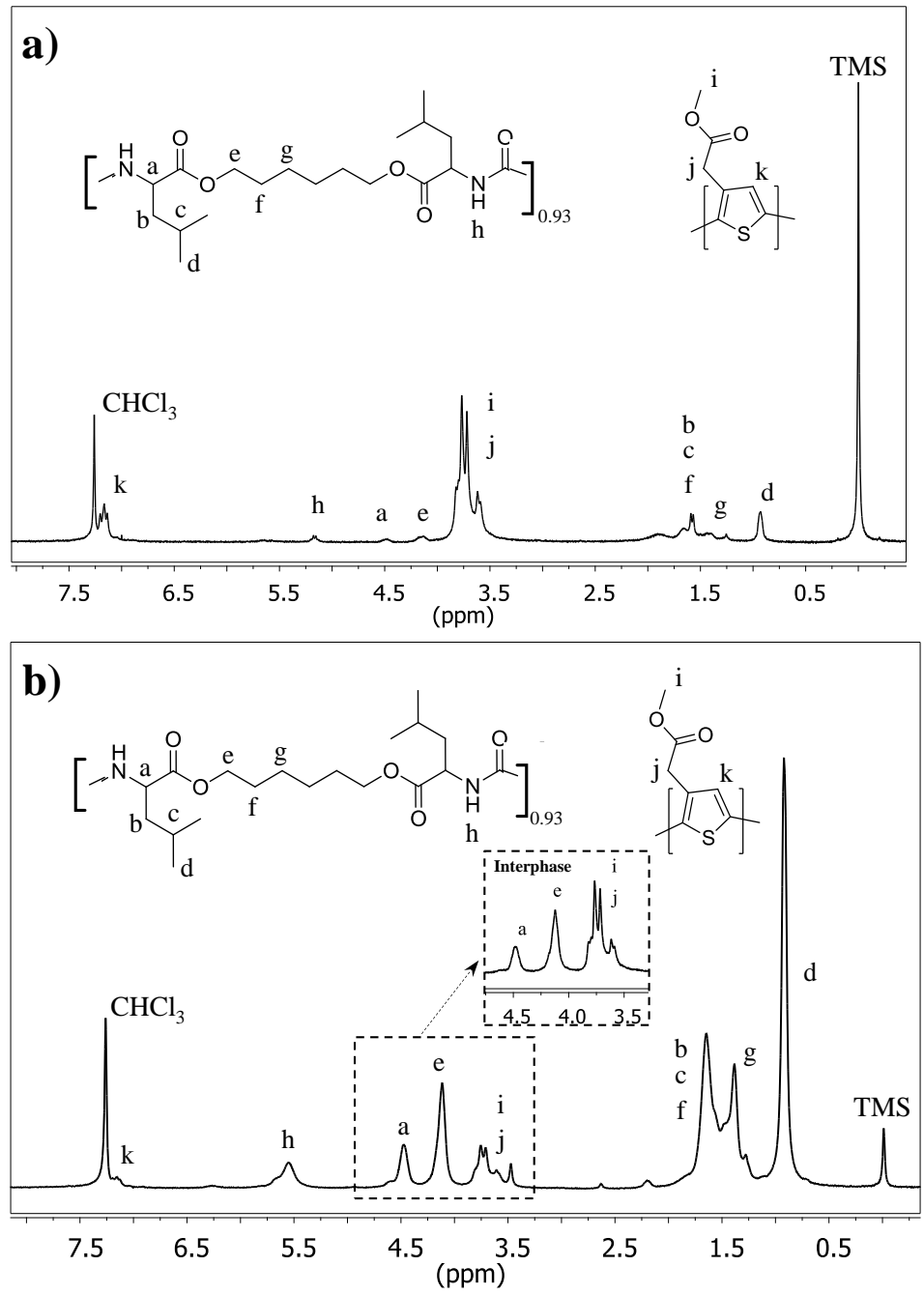

Figure 5 


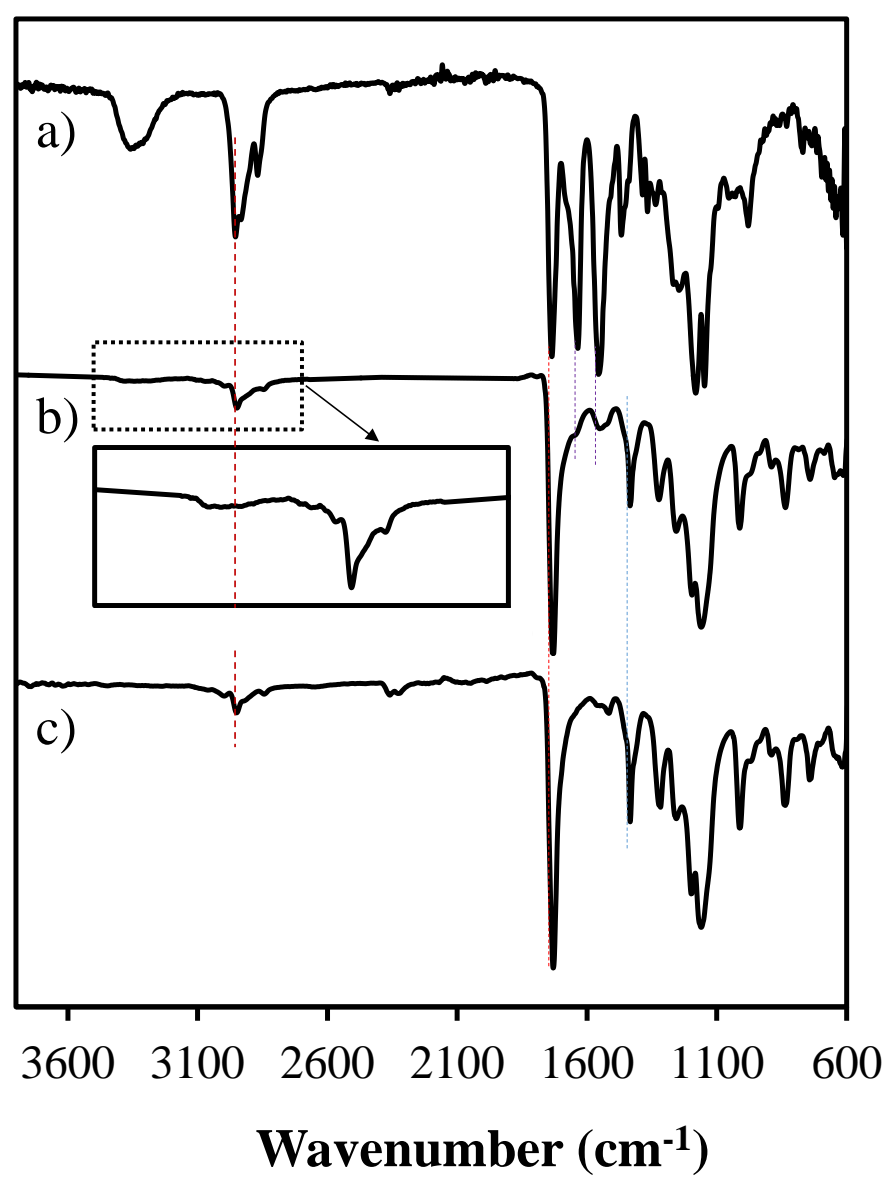

Figure 6 
a)

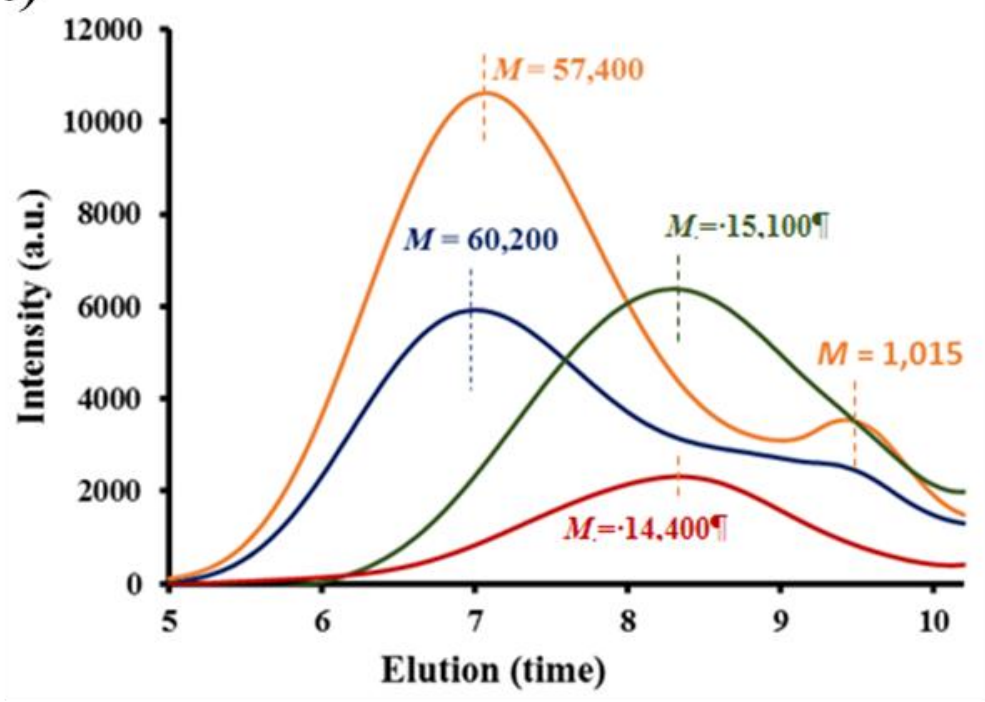

b)

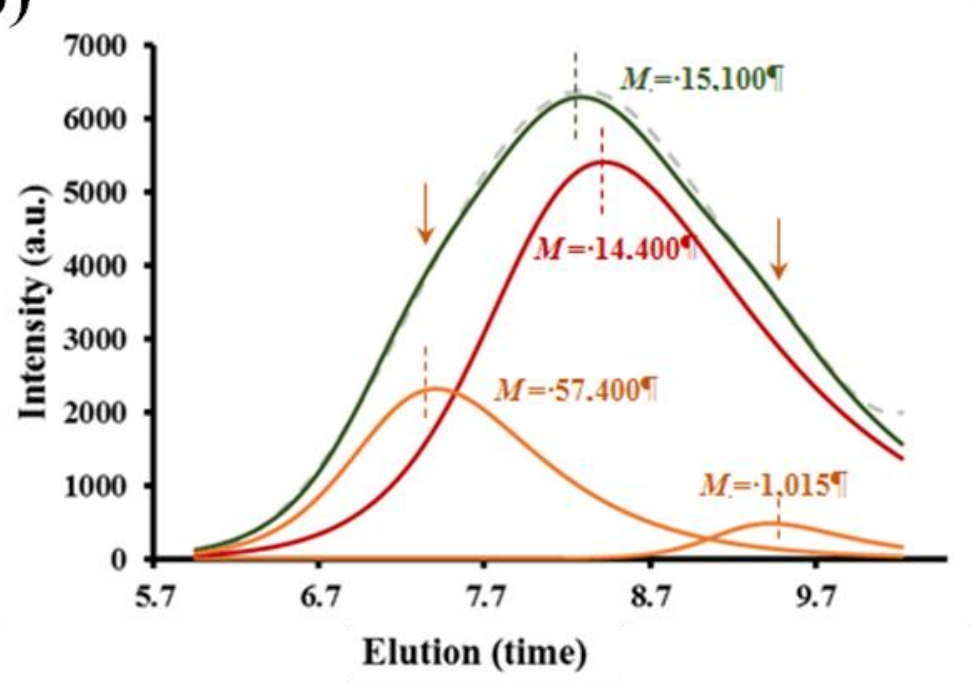

Figure 7 


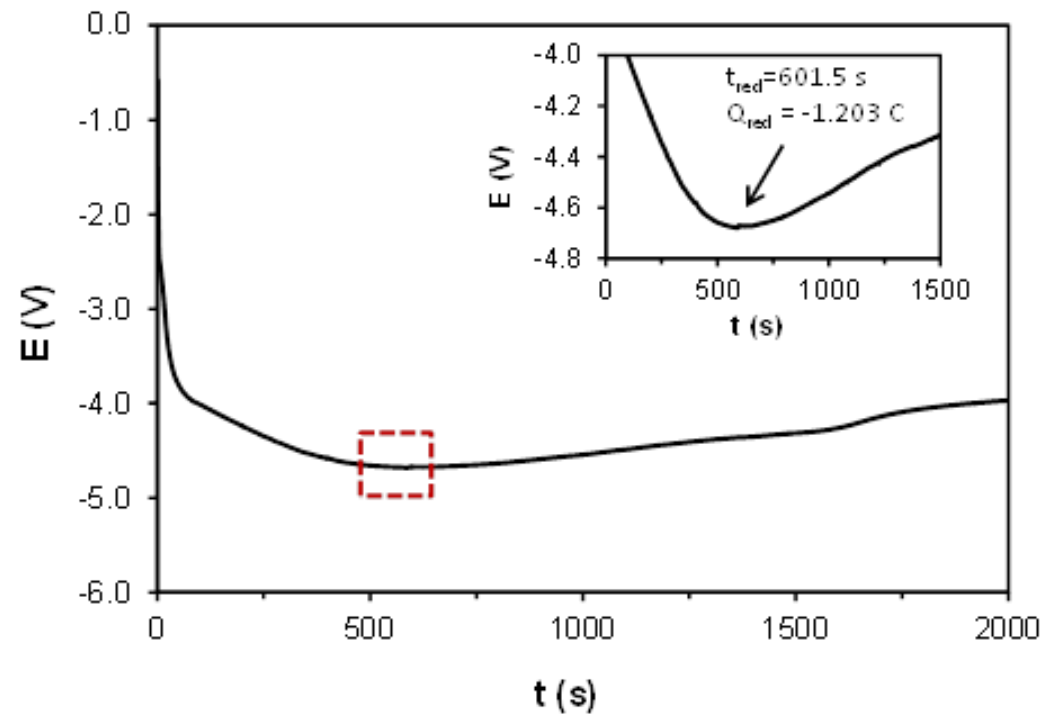

Figure 8 

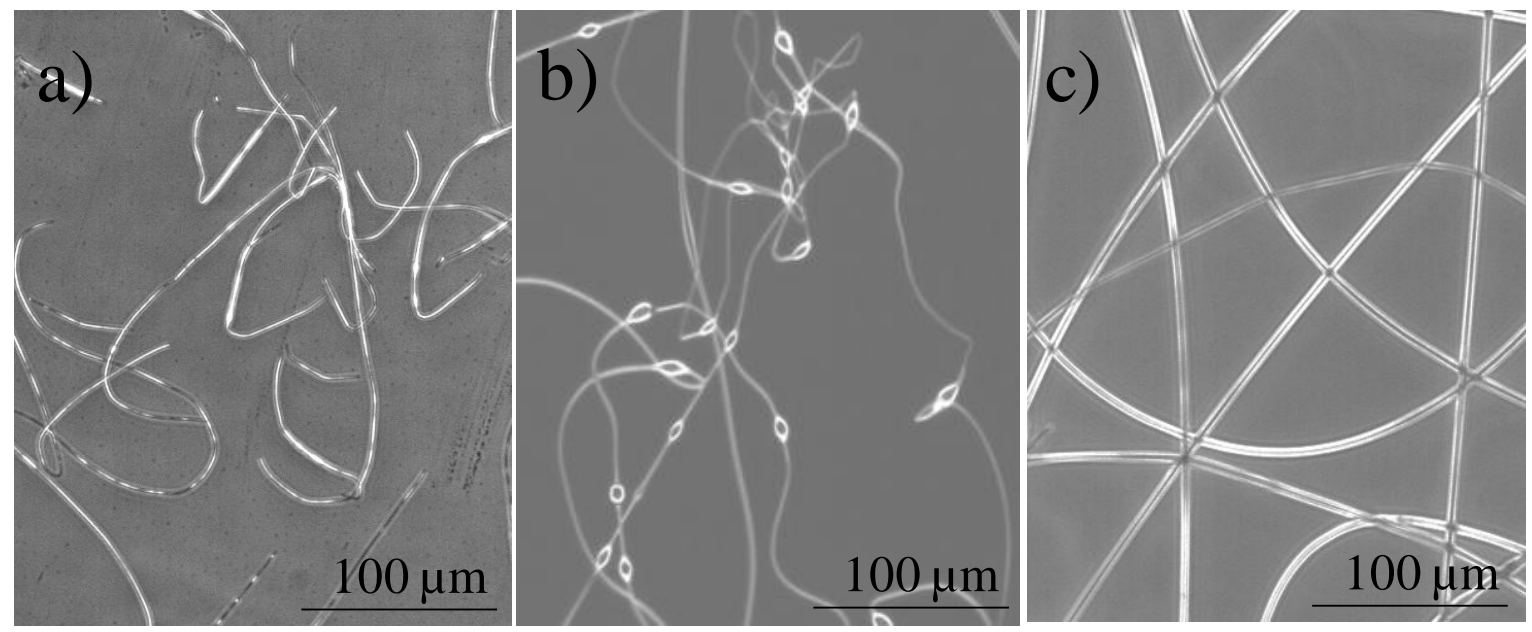

$20 \mathrm{KV}, 1.0 \mathrm{~mL} / \mathrm{h}, 24 \mathrm{~cm} 20 \mathrm{KV}, 2.5 \mathrm{~mL} / \mathrm{h}, 24 \mathrm{~cm} 25 \mathrm{KV}, 3.5 \mathrm{~mL} / \mathrm{h}, 24 \mathrm{~cm}$ ELECTROSPINNING PARAMETER'S OPTIMIZATION

Figure 9 
a)

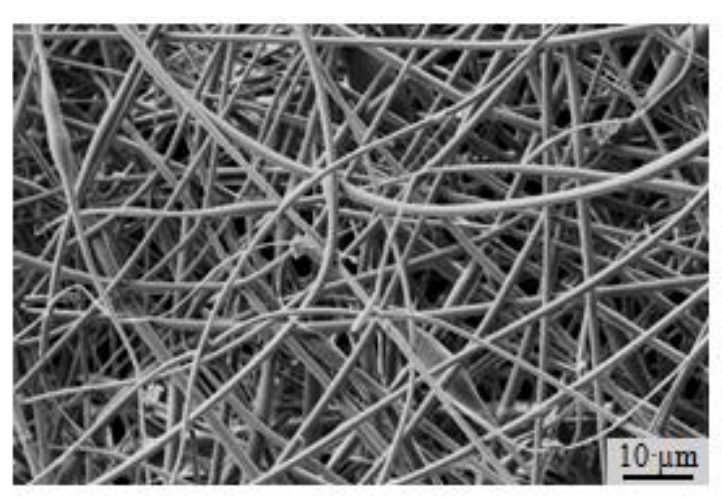

b)

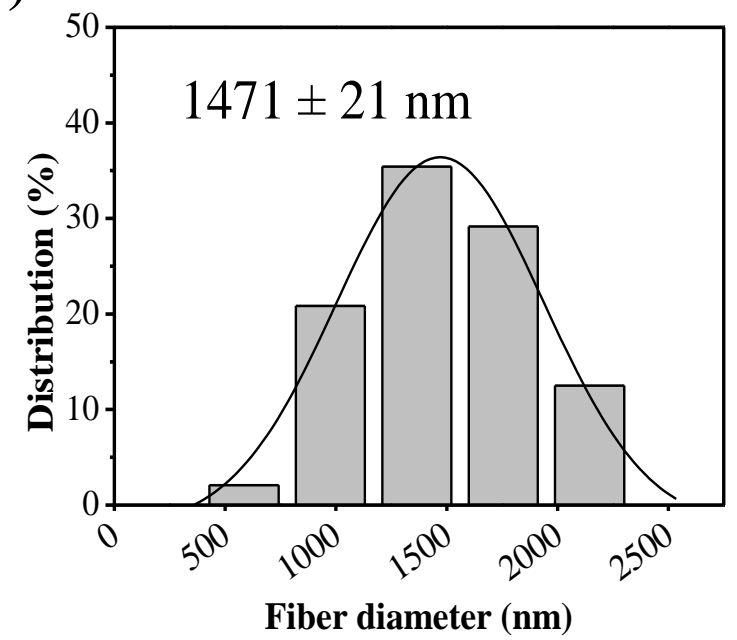

Figure 10 


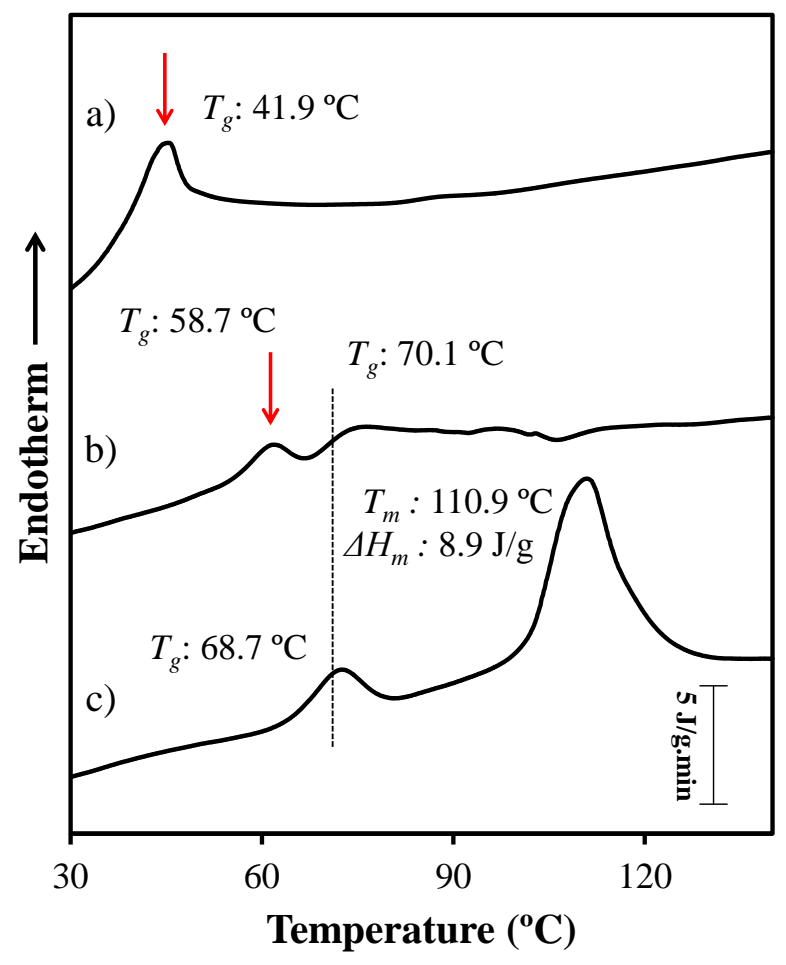

Figure 11 


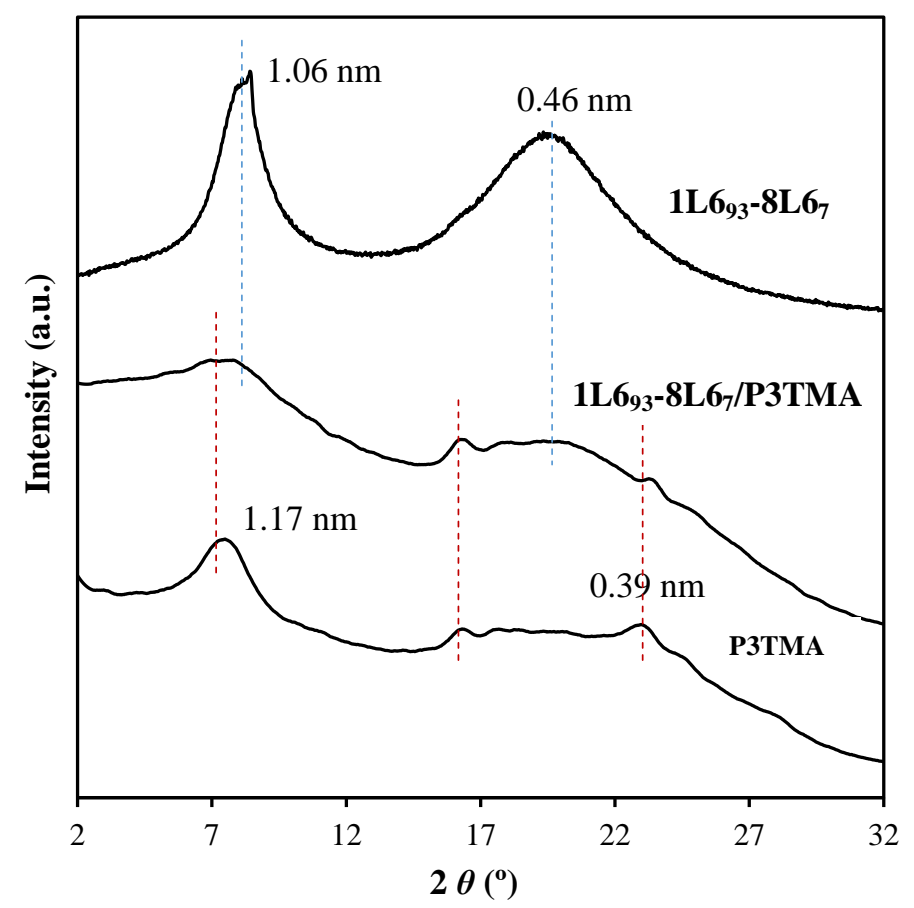

Figure 12 


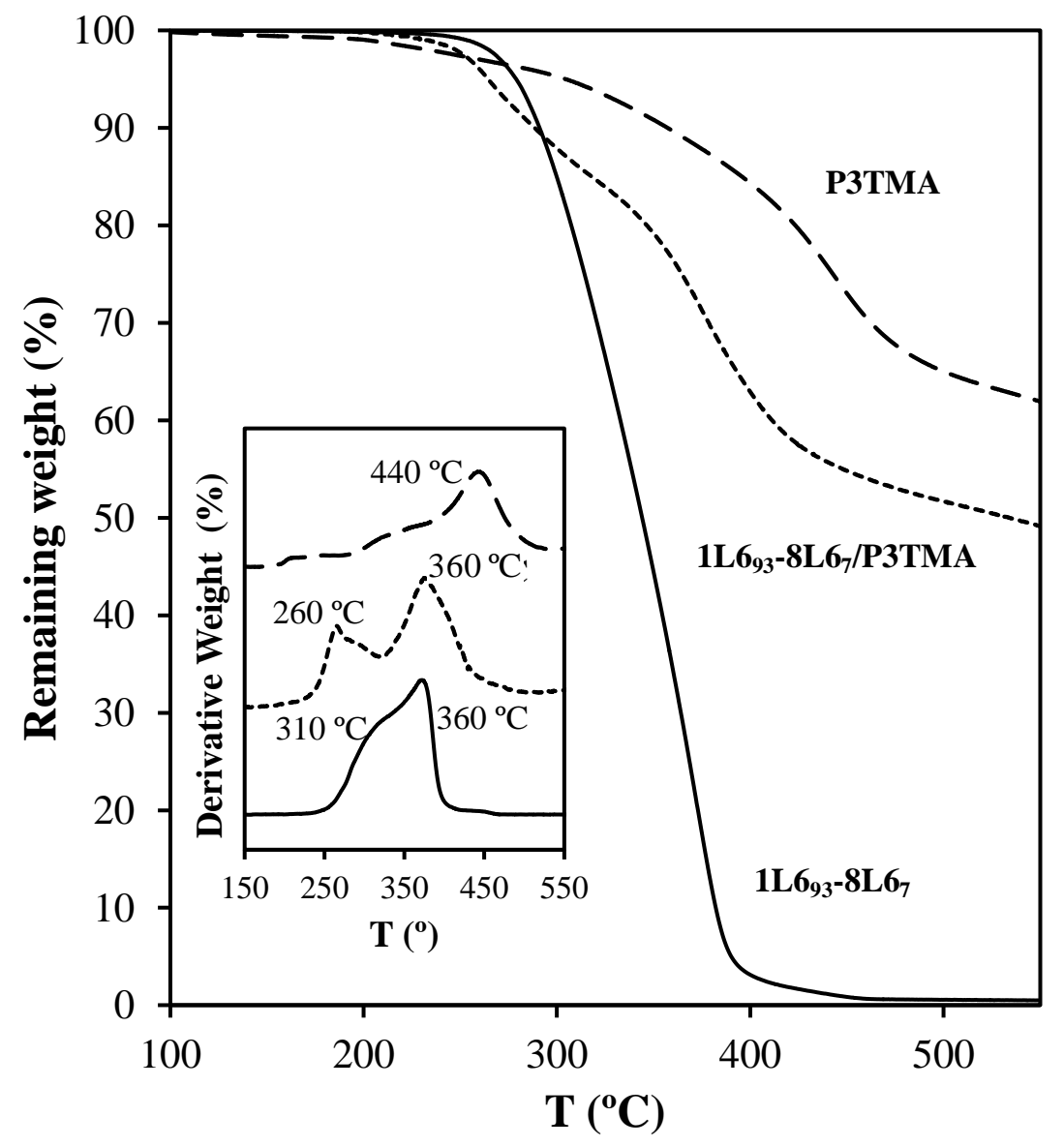

Figure 13 

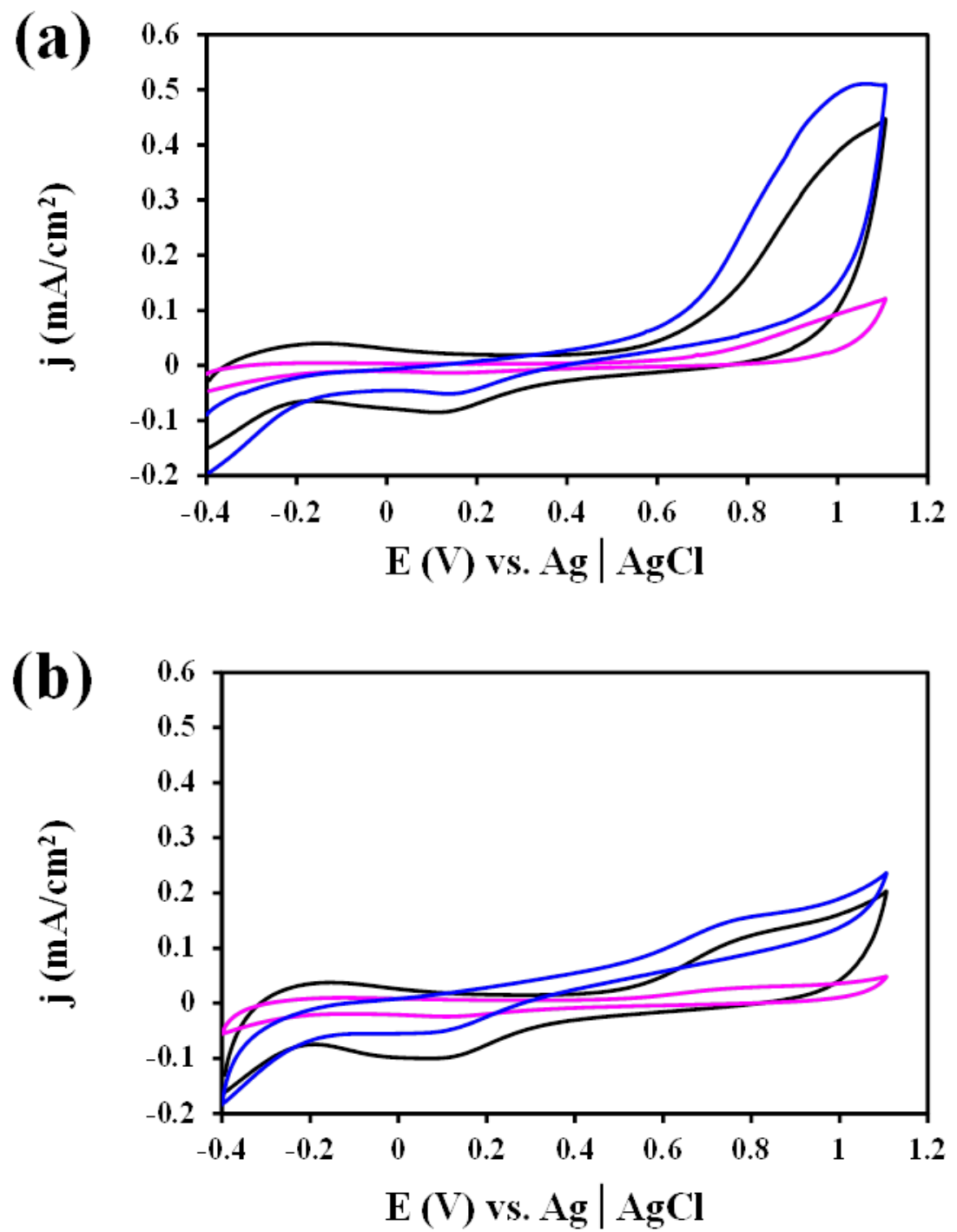

Figure 14 


\section{Graphical Abstract}

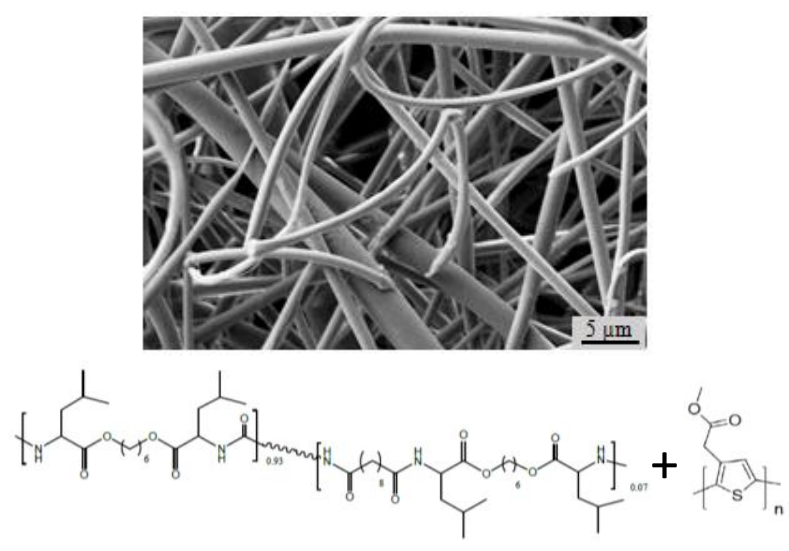

Electroactive scaffolds with up to $90 \mathrm{wt}-\%$ of polythiophene have been prepared by electrospinning using a poly(ester urea) carrier 